RADIATION CONSIDERATIONS FOR SUPERCONDUCTING FUSION MAGNETS

Mohamed A. Abdou

$$
\text { Prepared for }
$$

International Meeting

on Radiation Effects

on Superconductivity

Argonne National Laboratory

Argonne, I11inois

June $13-16,1977$

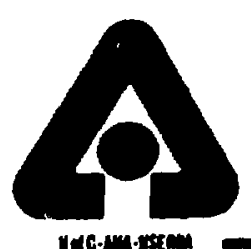


The facilities of Argonne National Laboratory are owned by the United States Government. Under the terms of a contract (W-31-109-Eng-38) between the U. S. Energy Research and Development Administration, Argonne Universities Association and The University of Chicago, the University employs the staff and operates the Laboratory in accordance with policies and programs formulated, approved and reviewed by the Association.

\section{MEMBERS OF ARGONNE UNIVERSITIES ASSOCIATION}

The University of Arizona Carnegie-Mellon University Case Western Reserve University The University of Chicago University of Cincinnati Illinois Institute of Technology University of lllinois Indiana L'niversity lowa State University The University of Iowa
Kansas State University The University of Kansas Loyola University Marquette University Michigan State University The Universily us Mi....igan University of Minnesota University of Missouri Northwestern University University of Notre Dame
The Ohio State University Ohio Iniversity The Pennsylvania State University Purdue University Saint Louis University Scuthern Illinois University The University of Texas at Austin Washington University Wayne State University The University of Wisconsin

\section{NOTICE}

This repert was prepared as an account of work sponsored by the United States Governmest. Neither the Lnited States nos the United States Energy Reseateh and Development Administration, nor any of their employees, nor any of their contractors, subcontracters, or their employees, makes any warranty, express or implied. or assumes any legal liability or responsibility for the accuracy, completencss or usefulness of any infurmation, apparatus, product or process disclosed, or represents that its use would not infringe privately-ownerl rights. Mention of comnercial products. their manufacturers. or their suppliers in this publication does not imply or connote approval or disapprusal of the product by Argonne Nationa: Laboratory or the U. $\ddot{3}$. Enzrgy Research and Development fidministrition. 
Paper presented at International Meeting on Radiation Effects on Superconductivity, Argonne National Laboratory, Argonne, Illinois, June 13-16, 1977; and for publication in Journal of Nuciear Materials.

RADIATION CONSIDERATIONS FOR SUPERCONDUCTING FUSION MAGNETS*

\author{
Mohamed A. Abdou \\ Applied Physics Division \\ Argonne National Laboratory \\ Argonne, Illinois 60439
}

Submitted July 1977

By acceptance of this aricle, the publisher or iecilient acknawiedges the U. :3. Governenent's right to retain a nonexclusive, iovalty free license $m$ and to any copvight covering the article.

"Work supported by the U. S. Energy Rescarch and Development Administration. 


\title{
RADIATION CONSIDERATIONS FOR SUPERCONDUCTING FUSION MAGNETS ${ }^{\star}$
}

\author{
Mohamed A. Abdou \\ Applied Physics Division \\ Argonne National Iaboratory \\ Argonne, Illinois 60439
}

\section{Abstract}

Superconducting magnets are believed to be necessary for fusion power reactors. High flux levels of neutrons and secondary gamma rays in these reactors require extensive radiation shielding to protect the components of the superconducting magnets from intolerable radiation damage and energy deposition. Components that are particularly sensitive to radiation are the superconductor, the stabilizer, and the insulators.

In this paper, radiation environment for the magnats is characterized for various conditions expected for tokamak power reactor operation. The radiation levels are translated into radiation effects using available experimental data. The impact of the tradeoffs in radiation shielding and the change in the properties of the superconducting magnets on reactor performance and econcmics is examined. It is shown that (1) superconducting magnets in fusion reactors will operate at much higher radiation level than was previously anticipated; (2) additional data on radiation damage is required to better accuracy than is presently available in order to accurately quantify the change in properties in the superconducting magnet components; and (3) there : is a substantial penalty for increasing (or overestimating) the shielding requirements. Therefore there is a strong incentive to explore 
all important options that lead to lower radiation damage at a given radiation iever.

A perspective of future tokamak power reactors is presented and questions relating to desirable magnetic field strength and selection of materials for superconducting magnets are briefly examined.

\section{Introduction}

Fusion reactors based on magnetic confinement employ a variety of magnets for initiating, driving, confining, and shaping the plasma. Many of these magnets are large in size and are required to provide a high field. Although fusion reactors appear to be viable with normal magnets, the development of superconducting magnets is believed to be necessary for these reactors on the grounds of better economics and reliability. Much of the energy liberated in a fusion reactor operated on the $D-T$ or $D-D$ cycle is carried away with neutrons. Therefore, knowledge of radiation effects in the components of superconducting magnets is of great importance to fusion reactor research and development.

The largest effort in the world fusion power reactor research and development program is devoted to tokamaks operated on the D-T cycle. The scope of this paper is limited to this class of reactors but many of the ideas can be extrapolated to other types of magnetic confinement reactors.

The need for radiation protection of superconducting magnets has been realized [7-5] by tokamak shield designers since the early stages of tokamak development. Attempts were made to derive tolerable radiation levels in superconducting magnets as a necessary step in arriving at a sound radiation shield design. Until recently there was a lack of information that can permit quantifying the radiation effects in the components of the superconducting magnets. Refrigeration requirements were generally used as the limiting factor for shfield 
design. The general guiding philosophy for shield designers was to reduce the radiation field at the magnet to the lowest possible level. Consequently, earlier iterations on tokamak reactor designs resulted in very thick radiation shield. Later, attempts were made to review the characteristics of the radiation environment in the superconducting magnets. Unfortunately these reviews used the results of the earlier designs as a fixed target for tokamak reactors and arrived at a misleading conclusion that radiation effects in the magnet are negligible.

At present, a second generation of tokamak reactor designs is evolving [6]. This second generation of designs is based on better understanding of the tradeoffs and interrelations within and among reactor components. In addition, codes are becoming available that allow parametric analyses and economic comparisons of a wide range of design parameters and options [7]. These studies show that the overa 11 reactor performance and economics favor shields that are considerably thinner than those employed in earlier designs. Consequently, the radiation level in the superconducting magnets is one to two orders of magnitude higher than was generally assumed in previous studies. These results have identified a greater need for more accurate information on radiation effects in the components of superconducting magnets than is presently known.

The next section provides a brief review of tokamak reactor systems with emphasis on the interrelation between radiation shield and various types of magnets. Section 3 examines the results of trade-off studies pertinent to the shield design and radiation effects in superconducting magnets. In Section 4, radiation environment for the magnets is characterized for various conditions expected for tokamak power reactor operation. 


\section{Review of Tokamak Magnets and Shields}

The purpose of this saction is to briefly review the major features of tokamaks; particularly, the geometrical relationship between the radiation shield and the various types of magnets. Figures 1 and 2 show a perspective view and a vertical cross section of a typical tokamak reactor. The plasma is confined in a toroidal geometry with the cross section of the torus being circular, D-shaped, or doublet. In a D-T cycle, the fusion energy is liberated as kinetic energy of $3.5 \mathrm{MeV} \alpha$-alpha particles and $14.1 \mathrm{MeV}$ neutrons. The plasma region is surrounded by a vacuum vessel (first-wall) that serves as the vacuum boundary for the plasma chamber. The first wall is surrounded by a blanket that converts the kinetic energy of the neutrons into heat. The blanket has lithium in one form or another for tritium regeneration. The magnet shield surrounds the blanket. The basic function of the magnet shield is to provide the radiation attenuation necessary for protection of the components of the toroidal-field magnets.

\subsection{Types of magnets}

The toroidal-field (TF) coils constitute the largest magnet system in a tokamak. These coils generate a strong steady-state toroidal inagnetic field in the plasma region. The TF coils are closely packed on the inner side of the torus and the spacing between each pair of coils increases in the outward direction and reaches its maximum on the outside at the midplane. Each coil has a cross section that can be circular, oval or D-shaped. Constant tension D-shape is currently believed to be the most appropriate geometry for the TF coils. Tokamak operation requires a toroidal magnetic field at the plasma centerline of $4-8 \mathrm{~T}$ which corresponds to a maximum magnetic field at the coil windings of 27-14 T depending on many of the reactor design characteristics. 
In addition to the toroidal-field coil system, tokamaks require a poloidal coil system. The poloidal coils vary in position and requirements but they have the common geometrical feature of being a concentric set of circles with the toroidal axis as the common axis. The ohmic heating $(\mathrm{OH})$ coil system, a part of the poloidal coils, consists generally of a solenoid located inside the central core formed by the inner leg of the toroidal field coils and a number of smaller coils as indicated in figs. 1 and 2. The OH coils act as the primary side of a transformer with the plasma as the secondary side. Energizing the primary side incluces and drives a toroidal current in the plasma. The plasma current, in addition to providing for initial plasma heating, produces a pulsed poloidal magnetic field which together with the steady-state toroidal field confine the plasma. The pu?sed OH roils can be nomal or superconducting. It has been shown that a pulsed superconducting magnet is generally superior to a pulsed normal magnet unless the maximum field for a normal coil could be designed so as to be twice as high as the maximum field for a superconducting coil [8]. The $\mathrm{OH}$ coil system as described above and as shown in Figs. 1 and 2 is located outside the TF coil system. In this location, the winding configurations can be arranged so that the pulsing fields and the torques imposed on the TF coils are minimized. In addition, they receive less radiation than the TF coils do. However, another concept for tokamak reactor desigri has been proposed [9], in which the $\mathrm{OH}$ coils are located inside the bore of the TF coils. This concept is meritorius for several reasons but it causes the $\mathrm{OH}$ coils to be closer to the high radiation field.

A tokamak plasma requires a pulsed vertical field to provide control on the position of the plasma column. This field is provided by the equilibriumfield (EF) coils. Lower ampere-turn and better coupling to the plasma can be 
obtained by placing the EF coils in the blanket as close as possible to the first wall. However, the high radiation field and the high temperature make it difficult to design even normal copper coils for placement in the blanket. Much easier assembly, maintenance, and replacement of the EF coils can be accomplished by placing them outside the TF coils. Whether these coils can be normal or superconducting and whether they are in a severe or moderate radiation environment will depend on their location either inside or outside the TF coils. Detailed studies remain to be carried out to determine the best compromise for the location and type of the TF coils. Knowledge of radiation effects in superconducting magnets provides an important contribution to these studies.

Tokamaks with Doublet plasma require field-shaping coils (F-coils) to actively shape the plasma [10] (see fig. 3). Because of the extensive shaping capability requirements on these coils they must be sufficiently close to the plasma. Moving the F-coils away from the plasma increases significantly the total current requirements. On the other hard, coils located in proximity to the first wall wiil be subjected to a very intensive radiation field which will certainly shorten considerably the useful lifetime of any type of magnet. A11 poloidal coils such as the F-coils that are located inside the toroidal-field coils are extremely difficult to repair and replace. This is particularly complicated by the fact that remote handling is a necessity. Normal, cryoresistive, and superconducting magnet options have been considered [10] for the F-coils. Operation of normal coils will involve large Joule heating losses but superconducting magnets will also require a high refrigeration power requirement for removal of nuclear energy deposition. Radiation effects in superconducting coils are very large but they are also of considerable concern for normal coils as well. Therefore, the best option for the type of F-coils is not clear yet. 
However, designing workable and maintainable F-coils with tolerable power losses in an intense radiation environment appears at present to be the most challenging engineering problem for Doutiet tokamaks.

\subsection{Material options for the magnets}

The number of materials that have been proposed for superconducting fusion magnets is rather limited. These materials are discussed below to provide a guideline for priorities in experimental programs concerned with radiation effects in superconducting fusion magnets.

Both $\mathrm{NbTi}$ and $\mathrm{Nb}_{3} \mathrm{Sn}$ have been proposed for the superconductor. $\mathrm{NbTi}$ is generally preferred because of its ductility but it has the disadvantage that the maximum practical magnetic field is limited to 8-10 T. Nib ${ }_{3} \mathrm{Sn}$ can be operated at much higher fields but its brittleness cast some doubt on its viability as a superconductor in large magnets. The brittleness of $\mathrm{Nb}_{3} \mathrm{Sn}$ dictates that the magnets be designed to a relatively low strain level of 20.05 to $0.1 \%$. At a low strain leve1, toroidal-field magnets with a peak field of 10-14 T are very thick and it becomes extremely difficult to design a workable $\mathrm{OH}$ coil system with a solenoid located in the central core [1]]. It has been shown [6] that under these conditions tokamaks are best operated with $\mathrm{NbTi}$ superconductors in the range of 8-9 T. However, high field superconductors such as $\mathrm{Nb}_{3} \mathrm{Sn}$ remain as strong contenders for fusion magnets.

The toroidal-field magnet system in tokamaks has a tremendous amount of stored energy of $110^{10}-10^{12}$ Joules. Therefore, it is necessary that these magnets be well protected and designed so that they do not quench. Cryostatically stable magnets are presently the preferred design option but intrinsically stable magnets have also been considered. Both copper and aluminum have been considered for the conductor stabilizer. Aluminum has a potential 
for lower intrinsic resistivity and magneto-resistance than for copper. In addition, the long-term radiation-induced activity in aluminum is much lower than that induced in copper. However, aluminum has a low yield stress and under some circumstances the resistivity increases excessively with strain. In addition, the radiation-induced resistivity in aluminum is approximately 2.5 times that in copper. At present, scpper is assumed to be the preferred choice for near-term fusion magnets with aluminum as a very attractive longterm possibitity.

Steel is generally considered to be the primary choice for structural material in the magnet. However, dluminum alloys have been considered as the structural materiais in magnets that employ aluminum stabilizers.

A variety of insulators are required in the magnets. Up to the present, only organic insulators have been considered for the TF magnets because they exhibit the ductility required for large coil windings. As will be shown 1:ter in this paper, the low threshold for radiation damage in organic insulators result in significant economic penalty for tokamaks. The higher threshold for radiation damage in inorganic insulators make them attractive for fusion magnets but their brittleness present a very serious 1 imitation on their practical lise, particularly in large coils such as the TF magnets. All coils that have to be located inside the blanket/shield must be designed, however, to employ inorganic insulators as it appears very doubtful that organic insulators can withstand the harsh radiation environment in the blanket/shield for a reasonably long operation time.

\subsection{Radiation shields}

Figure 4 is a vertical cross section of a tokamak which is similar in many respects to fig. 2 but many of the engineering details are omitted to facilivate the following discussion. The sector of the blanket and shield on the inner side of the torus is normally called the inner blanket/shield. The rest of the blanket 
and shield on the top, bottom, and outer regions of the torus is referred to as the outer blanket/shield.

The inner blanket/shieid occupies the high magnetic field region where space is at a premium. Therefore, the main objective of the design for the inner blanket/shield is to privide protection for the TF coils with the smallest possible thickness, $\Delta_{B S}^{i}$, from the first wali to the magnet. One means of accomplishing this goal is to use very efficient shielding materials. A combination of stainless steel (SS) and/or tungsten and boron carbide $\left(B_{4} C\right)$ has been found to be a reasonably good choice for this purpose. In addition, it is essential that shielding requirements for the TF coils are not overestimated. The next section presents results of the trade-offs concerned with $\Delta_{\mathrm{BS}^{\circ}}^{i}$

The space restrictions are much less severe on the outer blanket/shield. The outer blanket incorporates the tritium breeding medium which generally results in lower attenuation efficiency than that in the inner blanket. Several materials have been proposed for use in the outer shield; e.g. lead, lead mortar, borated graphite, water, boron carbide, and nonmagnetic concrete. Combinations of two (high mass number and lighter material) or more of these materials provide good shielding composition but they generally result in less attenuation efficiency than a mixture of stainless steel-boron carbide or tungsten-boron carbide generally employed in the inner shield. Therefore, the outer blanket/shield thickness, $\Delta_{\mathrm{BS}}^{0}$, is generally considerably greater than $\Delta_{\mathrm{BS}}^{i}$ to provide the same level of radiation attenuation. In some design concepts, additional attenuation is proyided for on the outside by further increase in $\Delta_{B S}^{0}$ in order to reduce the overall refrigeration power requirement in the TF magnets. Because of these considerations, toroidal-geometry, and the particular geometrical shapes of the TF magnets the neutron and gamma-ray fluxes vary from one position to the other along the circumference (in the poloidal direction) of the TF magnets. The maximum fluxes 
in almost all designs occur in the midplane at the inner side of the torus at the Inner layer of the magnet that is closest to the shield, i.e. the location marked $A$ in fig. 4. Neutrons and secondary gamma rays are also attenuated within the magnet (e.g. along lines $C-D$ and $A-B$ in fig. 4) as the composition of the magnet (copper or aluminum and stainless steel) is a good radiation attenuator.

Tokamak reactors require that the blanket and magnet shield accommodate a variety of penetrations, including those for vacuum pumping, auxiliary heating, divertor, and maintenance access. Many of these penetrations are large open regions which extend fron the first wall radially outward through the blanket/ shield and between the TF coils. Figure 2 shows an example of penetrations for neutral beams. These penetrations seriously affect the attenuation efficiency of the magnet shield and cause considerable radiation streaming into the toroidal and poloidal coils. Special penetration shields have to be designed to protect the magnets and other reactor equipment $[16,15]$. However, even fully shielded penetrations cause a considerable change in the characteristics of the radiation field within the magnets.

\section{Radiation Shield/Superconducting Magnet Tradeoff}

A very notable characteristic of a tokamak reactor is a strong and complex ...interface among reactor components. The interface between the toroidal field magnet and the radiation shield is particularly strong and involved. Understanding and accounting for this interface is extremely important for shieid and magnet designers and those involved in information development for these reactor subsystems. This section delineates this interface and its important impact on the overall reactor performance.

A primary function of the blanket/shield system is to protect the superconducting toroidal-field coils from excessive radiation. The radiation level at the magnet depends on the composition and thickness of the blanket/shield. The 
problem of finding an effective shield composition has been examined in detail earlier $[3,4,12]$ but the designer's choice is limited to naturally occurring materials as well as engineering considerations. For the same shield composition, varying the shield thickness has many counteracting effects on the reactor performance and economics. The contradicting requirements on the shield thickness are discussed next as they demonstrate the large impact that radiation effects in superconducting magnets have on tokamaks. The discussion in this section should also clarify why the present generation of tokamak designs involve higher radiation levels at the magnets than those in earlier design generations.

\subsection{Motives for smaller shield thickness}

The power density in a tokamak can be written as

$$
F \propto B_{t}^{2} B_{t}^{4}
$$

where $\beta_{t}$ is the plasma kinetic-to-magnetic pressure ratio and $B_{t}$ is the toroidal field strength at the center of the plasma. Thus, increasing $B_{t}$ and/or $B_{t}$ can result in significant increase in reactor power. Practical reactors operate with a power density of $u$ to $10 \mathrm{NW} / \mathrm{m}^{3}$. The magnetic field strength required to obtain a power density in this range depends strongly on $\beta_{t}$. The plasma stability limit on $\beta_{t}$ has not been established yet. Current investigation in the field of plasma physics indicates that $\beta_{t}$ is likely to be in the range of 0.04 to 0.1 . Therefore, the most desirable value for $B_{t}$ is not certain at present. Tokamak reactor designs have considered $B_{t}$ in the range 3-8 T.

A limit on $B_{t}$ comes from technological constraints on the maximum practicai magnetic iield, $B_{m}$, at the TF magnet windings. The value of $B_{t}$ depends upon $B_{m}$ and upon the geometry according to 


$$
B_{t}=B_{m}\left(1-\frac{1}{A}-\frac{\Delta_{v}}{R}-\frac{\Delta_{B S}^{i}}{R}\right),
$$

where $A$ is the aspect ratio (typically $2.5-5$ ), $R$ is the major radius of the plasma torus $(4-14 \mathrm{~m})$, and $\Delta_{v}$ is the thickness of the scrape-off region between the plasma and first wall $(0.1-0.5 \mathrm{~m})$. The parameter $\Delta_{\mathrm{BS}}^{i}$ is the distance in midplane on the inner side of the torus from the first wall to the TF coil windings. The largest portion of $\Delta_{B S}^{i}$ is occupied by the inner blanket/shield but it also includes maintenance clearance space, and the cryostat dewar, thermal and magnetic shield, and bobbin of the TF coils. The maximum toroidal field strength $B_{m}$ is limited by the type of superconductors. Fields $B_{m} \leqslant 9 T$ are achievable with NbTi superconductor but at higher fields $\mathrm{Nb}_{3} \mathrm{Sn}$ would be required.

Equations (1) and (2) show the importance of the inner blanket/shield thickness, $\Delta_{\mathrm{BS}}^{i}$. For a given $\mathrm{B}_{\mathrm{m}}$, increasing the blanket/shield thickness reduces the field in the plasma region and results in a significant decrease in the reactor power. Curve a in Fig. 5 shows the reactor power as a function of $\Delta_{B S}^{i}$ for a reactor with $A=2.5$ and $R=8 \mathrm{~m}$ and blanket shield composition of SS/SS-B $\mathrm{B}_{4} \mathrm{C}$. As can be noticed from the graph, increasing $\Delta_{\mathrm{BS}}^{i}$ from $0.8 \mathrm{~m}$ to $1.4 \mathrm{~m}$ reduces the power by roughly a factor of 2 .

Another way to illustrate the importance of reducing the blanket/shield thickness on the inner side of the torus is to examine a reactor with a fixed aspect ratio, major radius, and magnetic field at plasma centerline. Under these conditions the reactor power output is fixed for the same plasma parameters. Two effects can now be noted if the blanket/shield thickness, $\Delta_{B S}^{i}$, is increased:

(1) It is clear from eq. (2) that the maximum field, $B_{m}$ at the TF windings $\because$ increases. The cost of the TF magnet increases as $\sim B_{m}^{2}$. 
(2) The thickness, $\Delta_{m}$, of the TF magnet increases roughly as $\sim \mathrm{P}_{2 i^{*}}$ If $\mathrm{B}_{\mathrm{m}}$ exceeds $\approx 9 \mathrm{~T}$ then $\mathrm{NbTi}$ cannot be used and $\mathrm{Nb}_{3} \mathrm{Sn}$ superconductor (or alternative) has to be employed. Because of $\mathrm{N}_{3} \mathrm{Sn}$ brittleness the maximum permissible strain is a factor of $\sim 2$ to 3 lower than that with AbTi. This dictates a large increase in the magnet thickness since $\Delta_{m}$ is inversely propumtional to the design strain. As shown in figs. 1 and 2, a central support cylinder is required to take up the compressive force pushing the TF coils toward the tokamak axis. The thickness of the support cylinder, $\Delta_{s p}$, increases as $B_{m}$ increases. The flux core radius, $r_{v}$, for the $\mathrm{OH}$ coils is given by

$$
r_{v}=R-\Delta_{v}-\Delta_{B S}^{i}-\Delta_{m}-\Delta_{s p}
$$

Therefore, increasing $\Delta_{B S}^{i}$ increases also $\Delta_{m}$ and $\Delta_{s p}$ and results in significant reduction in $r_{v^{*}}$. The maximum ohmic heating field, $\mathrm{B}_{\mathrm{OH}}$, increases as $r_{v}$ is decreased, $B_{\mathrm{OH}} \sim 1 / r_{\mathrm{V}}^{2}$. Increasing $B_{\mathrm{OH}}$ increases the cost of the pulsed $\mathrm{OH}$ coils and more importantly the cost of the $\mathrm{OH}$ power supplies.

These effects are demonstrated numerically in figs. 6, 7, and 8. Shown in these figures are $B_{m}, r_{v}$, and $B_{O H}$ as functions of $\Delta_{B S}^{i}$ for $R=6,7,8$, and $9 \mathrm{~m}$. In calculating these results NbTi magnets with a design strain of $0.2 \%$ were employed for $\mathrm{B}_{\mathrm{m}} \leq 9 \mathrm{~T}$ and $\mathrm{Nb}_{3} \mathrm{Sn}$ magnets with a design strain of $0.1 \%$ were used at higher fields. In all cases shown in these figures, the plasma is circular with an aspect ratio of 3 and a fixed neutron wall loading of $3 \mathrm{~mW} / \mathrm{m}^{2}$.

\subsection{Motives for Larger Shield Thickness}

All the effects discussed so far indicate very strong reasons for reducing the blanket/shield thickness. Magnet protection, on the other hand, requires increasing this thickness. The neutron flux, $\phi_{m}$, at the inner TF coil winding is correlated to the neutron flux, $\phi_{w}$, at the first wall by the approximate relationship 


$$
\phi_{m}=\phi_{w} e^{-\mu_{b s} \Delta_{B S}^{i}}
$$

where $\mu_{b s}$ is an effective attenuation coefficient which depends strongly on the material composition of the blanket/shield and for typical shielding materials it varies from $20.03 \mathrm{~cm}^{-1}$ to $20.14 \mathrm{~cm}^{-1}$. From magnet protection viewpoint, it is desirable to use a large ${ }^{i} \mathrm{rS}^{\circ}$. This conficts with the deletorius effects that an excessively large $\Delta_{B S}^{i}$ has on reactor performance and economics. Therefore, a prudent compromise on $\Delta_{\mathrm{BS}}^{i}$, and hence the operating radiation level at the magnet, has to be found. A cricial step for doing this is to accurately quantify the performance and economics effects of radiation on the superconducting magnets. An attempt to perform this is made next.

Radiation damage to the magnets is particularly important in three areas: (a) effects on the individual magnet components under steady-state irradiation; (b) possible synergistic effects in large superconducting coils; and (c) any effects that may result from periodic magnet annealing. In general, no data exists at the present time to evaluate effects in (b) and (c). On the other hand, very useful, but limited expe imental inforamtion are available with which to evaluate radiation effects in the magnet components. The components of concern are (1) the superconductor; (2) the normal (stabilizing) conductor; (3) insulators; and (4) structural materials.

We will now utilize the available experimental inforamtion on radiation effects in individual magnet components to examine their impact on the magnet and reactor performance and economics. Our concern here is not to survey and investigate radiation damage in magnets but rather is to study the implications of changes in crucial performance properties. The former is covered somewhere else in the Proceedings of this meeting. 


\subsubsection{Superconductor}

It has been shown that high neutron fluences result in a change in the transition temperature $T_{c}$ and the critical current density, $J_{c}$ of superconductors. Furthermore, radiation effects in NbTi alloys are significantly different from those in the $\mathrm{Nb}_{3} \mathrm{Sn}$ compounds. To focus this discussion, we will consider only the case of $\mathrm{NbTi}$. For $\mathrm{NbTi}$, the change in $\mathrm{T}_{c}$ is very small, and the irradiation-induced changes in $J_{c}$ are quite sensitive to the metallurgical structure in the unirradiated material [16]. Results on the change in $J_{c}$ have been reported in the lilerature as a function of neutron fluences. Figure 9 shows the neutron fluence, $\phi t$, in a NbTi superconductor as a function of the inner blanket/shield thickness, $\Delta_{B S}^{i}$ for $I_{w}=1$ and $30 \mathrm{~mW}-y \mathrm{r} / \mathrm{m}^{2}$, where $I_{w}$, integral neutron wall loacing, is the product of $P_{w}$, the neutron wall loading, and an operational time period, $t_{0}$. The composition of the blanket/shield is similar to that of fig. 5, i.e. stainless and boron carbide. The value of $\Delta_{\mathrm{BS}}^{i}$ in this figure, and everywhere else in this paper, inclucies provision for $10 \%$ of the blanket/shield volume as void to account for a variety of cooling, clearance, and other engineering requirements in addition to a fixed $0.05-\mathrm{m}$ vacuum gap generally required in the TF coils for thermal insulation.

Experimental results for tine change in the critical current density of NbTi with neutron fluence up to $5 \times 10^{22} \mathrm{~m}^{-2}$ can be approximated [17] as

$$
J_{c}=J_{c o} e^{-\alpha \phi t}
$$

where $J_{c 0}$ is the unirradiated value for the critical current density and $\alpha=3.5 \times 10-24 \mathrm{~m}^{2}$.

Figure 9 shows three horizontal $l$ ines that are representative of the experimental results on the relative change in the NbTi critical current density, $\Delta J / J_{c}$ 
as a function of neutron fluences. As can be inferred from these resultis, no or little change in $J_{c}$ occurs at fluences $s 10^{21} \mathrm{n} / \mathrm{m}^{2}$. The decrease in $J_{c}$ is moderate for fluences up to $\sim 3 \times 10^{22} \mathrm{n} / \mathrm{m}^{2}$ where $\Delta \mathrm{J} / \mathrm{J}_{\mathrm{c}} \sim-10 \%$. At higher fluences, the decrease in $J_{c}$ is relatively large for smail increments in the neutron fluences.

The decrease in the critical current density can be accommodated by adding more superconductors to produce the same ampere-turn. This involves increasing the cost of the magnet but this increase can be offset by the benefits achievable when $\Delta_{B S}^{i}$ is reduced. Thus, the permissible decrease in the critical current density is not a fixed value but it is an economics problem that is amenable to optimization.

\subsubsection{Normal conductor}

Low-temperature irradiation of normal conductors serving as the stabilizers in superconducting magnets results in an increase in the electric resistivity. The experimental data of Brown, et al [18] were used to derive the following formula for radiation-induced resistivity in copper:

$$
\rho_{\mathbf{r}}=3 \times 10^{-7}[1-\exp (-563 \mathrm{~d})] \Omega-\mathrm{cm},
$$

Where the saturation resistivity for copper, $\rho_{s}$, is equal to $3 \times 10^{-7} \Omega-\mathrm{cm}$ and $d$ is the total number of a tomic displacement. A displacement energy, $E_{d}$, of $40 \mathrm{eV}$ was used for copper. The value of $E_{d}$ has very little effect except through normalization of the numerical factor (563) in the exponent of the exponential term in the above equation. A similar expression can be derived for aluminum:

$$
p_{r}=8 \times 10^{-7}[1-\exp (-366 d)] \Omega-c m,
$$


where the value of $E_{d}$ for aluminum was taken as $26 \mathrm{eV}$. Figure 10 shows the maximum radiation-induced resistivity in copper as a function of the blanket/shield thickness, $\Delta_{B S}^{i}$, for integral wall loadings, $I_{w}$, of 1 and $30 \mathrm{MW}-\mathrm{yr} / \mathrm{m}^{2}$. At small values of $\Delta_{\mathrm{BS}}^{i}$, the radiation-induced resistivity is equal to the saturation value and does not change when $\Delta_{B S}^{i}$ is increased up to $20.6 \mathrm{~m}$ for $I_{w}=30 \mathrm{MW}-y \mathrm{r} / \mathrm{m}^{2}$. Further increase in $\Delta_{\mathrm{BS}}^{i}$ reduces $\rho_{\mathrm{X}}$ rather rapidly.

Cryogenic stabilization criterion requires that the heat transfer from the stabilized superconducting matrix must be sufficient to transfer the $I^{2} R$ heat generated in the stabilizing inaterial when a flux jump occurs, i.e.,

$$
I^{2} \rho \leq \mathrm{aqP},
$$

where $I$ is the oeprating current in the stabilizer of a composite conductor which has gone normal, $\rho$ is the total resistivity of the stabilizer, $a$ is the normal conductor cross-sectional area, $q$ is the heat flux, and $P$ is the r.ooled perimeter of the composite. The total resistivity $\rho$ is given by

$$
\rho=\rho_{0}+\rho_{m}+\rho_{r},
$$

where $\rho_{0}$ is the intrinsic resistivity, $\rho_{m}$ is the magnetoresistivity, and $\rho_{r}$ is the radiation-induced resistivity.

The increase in the resistivity of the stabilizer can be accommodated without violating the cryostability condition by adding more stabilizer and modifying the conductor design. This results in an increase in the magnet cost. This increase in cost can be compensated for by the economics gain achievable with smaller $\Delta_{\mathrm{BS}}^{i}$. Thus, the problem of radiation damage to the stabilizer is primarily an economics consideration. 


\subsubsection{Magnet anneal}

The experimental observation that most of the radiation damage to the superconductor and stabilizer can be recovered by magnet annealing brings another important factor into the performance and ecsilumics tradeoffs. Thie neutron fluences at the magnet varies, of course, linearly with the irradiation period, $t_{0}$, or equivalently, the integral neutron wall loading, $I_{w}$, is proportional to $t_{0}$, for the same neutron wall loading, $P_{w}$. From the results shown in figs. 9 and 10, it can be seen that for the same radiation-induced change in the properties of the superconductor and stabilizer, reducing $I_{w}$ (i.e. reducing $t_{0}$ for the same $P_{W}$ / permits the selection of a significantly smaller $\Delta_{B S}^{i}$. Thus, it is logical that tokamak reactor designs plan on periodical magnet annealing. However, there are other additional problems involved here. Magnet warmup and cooldown require that the power plant be shut down. The downtime involved results in a reduced capacity factor for the plant and an increased cost of energy depending on the necessary downtime for magnet anneal. The minimum time period required for magnet warmup and cooldown without inducing intolerable strains in large magnets has not been established yet. Preliminary estimates of approximately two to three months have been made but a detailed study is required to provide more definite information. This study must alsc account for the accumulated effects, if any, resulting from repeating the magnet anneal several to tens of times during the plant lifetime ( $230 \mathrm{yr})$.

\subsubsection{Insulators}

Superconducting magnets employ a variety of electrical and thermal insulations. Organic insulators are believed to be necessary for large magnets since inorganic insulators are very brittle. There is a serious lack of irradiation data on insulators at low temperature [20]. It is known, however, that organic insulators are much less resistant to radiation damage than inorganic insulators. Furthermore, 
radiation damage in these insulators is irreversible. Therefore, the insulators in the TF coils must be designed to function properly for the lifetime of the plant, typically $230 \mathrm{yr}$. Figure 11 shows the maximum dose in the TF coil insulators as a function of $\Delta_{B S}^{i}$ at 30 and $300 \mathrm{MW}-\mathrm{yr} / \mathrm{m}^{2}$. Extrapolation of neutron irradiation data suggests dose limits of $210^{8} \mathrm{rad}$ and $210^{9}$ to $5 \times 10^{9} \mathrm{rad}$ for mylar and epoxy, respectively. (Regions indicated by the letters $M$ and $E$ in fig. 11.) Thus, the minimum $\Delta_{B S}^{i}$ is $\sim i .0-1.3 \mathrm{~m}$ for epoxy, and $21.28-1.48$ for mylar. REgion 1 in fig. 11 shows that with radiation damage limits on inorganic insulators of $210^{12}$ to $5 \times 10^{12} \mathrm{rad}$, the minimum $\Delta_{\mathrm{BS}}^{i}$ is 20.5 to $0.8 \mathrm{~m}$.

\subsubsection{Refrigeration requirements}

Another effect in the superconducting magnets that calls for a thicker shield is the refrigeration power required to remove the nuclear energy deposition since $2300 \mathrm{~W}$ of electric power are required per watt of therma input to $4^{\circ} \mathrm{K}$ refrigerators. Curve $\mathrm{b}$ in fig. 5 shows the net reactor power, i.e. the gross reactor power minus the power required to run the magnet refrigerators, as a function of $\Delta_{B S}^{i}$. At $\Delta_{B S}^{i} \sim 0.45 \mathrm{n}$, the reactor power is barely sufficient to run the refrigerators. At $\Delta_{B S}^{i} \approx 0.8 \mathrm{~m}$ half the reactor power is wasted on refrigeration requirements. At larger $\dot{\Delta}_{B S}^{i}$, the refrigeration power requirements decrease rafidly. The maximum net power occurs at $\Delta_{B S}^{\mathbf{i}} \sim 0.91 \mathrm{~m}$. The value of $\Delta_{\mathrm{BS}}^{\mathbf{i}}$ at which the net power is maximum is not overly sensitive to reactor parameters but it depends greatly on the material composition of the shield. From fig. 5, one notes that the maximum net power occurs when the fraction of the reactor electrical output spent on the refrigerators is $21.5 \%$. This is about a factor of 15 higher than the limit on refrigeration power suggested earlier in the literature. 


\subsection{Resuzts of tradeoffs}

An important conclusion to be made from the resilts shown above is that the design of the magnet shield in terms of material composition and thickness must evolve from a trade-off study for the particular system. A system program [7] for fusion power plants recently developed at Argonne National Laboratory (ANL) has built-in capabilities for performing this type of trade-off studies. This system program can parametrize performance and economics variables of all components in a tokamak power plant. All interrelations within and among reactor components are mathematically modeled into the program. For example, radiation levels at the magnet as predicted by a neutronics model are transformed into property changes of the magnet components which are fully accounted for in the magnet design and hence the cost [11].

An extensive study of the tradeoffs in the magnet/shield design has been carried out using the ANL System Program. An example of the results is shown in fig. 12. This figure shows the cost of energy as a function of the inner blanket/shield thickness for tokamaks with aspect ratio of 3 , and neutron wall loading of $3 \mathrm{MW} / \mathrm{m}^{2}$. The blanket/shield material composition is the same as that described earlier in this section (stainless steel-boron carbide) with the same provision for vacuum, engineering, and maintenance space. Results are shown for tokamaks with major radius $\mathrm{R}=6,7,8$, and $9 \mathrm{~m}$. Annealing of the superconducting toroidal-field magnets was assumed to coincide with the first-wall replacement which occurs every $11.4 \mathrm{yr}$ and requires downtime of 80 days. Niobiumtitanium was employed for fields $\leq 9 \mathrm{~T}$ and $\mathrm{Nb}_{3} \mathrm{Sn}$ was used for higher fields. The plant capacity factor is $\mathbf{0 . 9}$. The reference parameters fixed for all cases in fig. 12 are shown in table 1. 
The results in fig. 12 show that the minimum energy cost is obtainable with $\Delta_{\mathrm{BS}}^{\mathbf{i}} \sim 1 \mathrm{~m}$. The maximum values at the Tr magnets for the radiation-related parameters at the optimum blanket/shield thickness are shown in table 2. The results of these parametric studies show that with the present inforiation, superconducting magnets can tolerate neutron and gamma-ray fluxes of $210^{14} \mathrm{~m}^{-2}-\mathrm{sec}^{-1}$. Neutron and gamma-ray fluences of $5 \times 10^{22} \mathrm{~m}^{-2}$ and $3 \times 10^{22} \mathrm{~m}^{-2}$, respectively can te expected. This level of radiation is much higher than has been predicted from earlier generations of tokamak designs that employed much thicker shields. At $\Delta_{\mathrm{BS}}^{i} \sim 1 \mathrm{~m}$, the radiation-induced resistivity is $\sim 10^{-7} \Omega-\mathrm{cm}$ and the change in the NbTi critical current density is $\Delta J / J_{c} \approx-14 \%$. Figures $9-11$ show that radiation effects in the magnet are very sensitive to $\Delta_{B S}^{i}$ in the neighborhood of $\Delta_{B S}^{i} \sim 1 \mathrm{~m}$ and $I_{w}=30 \mathrm{Ml}-y \mathrm{r} / \mathrm{m}^{2}$. Therefore, there is a great demand for high accuracy on neutron and gamma-ray transport calculations, nuclear data, and radiation damage information in the superconducting magnet.

Additional interesting remarks can be made about the results in fig. 12. Increasing $\Delta_{B S}^{i}$ beyond the optimum value increases the cost of energy due to the larger capital cost when $\mathrm{B}_{\mathrm{m}}$ and $\mathrm{B}_{\mathrm{OH}}$ increase. The relative increase in the cost of energy is more significant at smaller major radius, $R$. This can be readily explained by examining eq. (2) which shows that the ratio $B_{m} / B_{t}$ increases as the ratio $\Delta_{\mathrm{BS}}^{i} / R$ increases. In other words, the gradient of the TF field is steeper and the space on the inner side of the torus is more valuable for smaller-size machines. On the other hand, decreasing $\Delta_{B S}^{i}$ below the optimum value results in a dramatic increase in the cost of energy that is not overly sensitive to $R$. This increase in the cost of energy results from an ircrease in the refrigeration power requirements and an increase in the capital cost of the magnet to accommodate the increased radiation level at the magnet. The radiation level at the magnet is not sensitive to $R$, when the neutron wall load is fixed. 
Figure 13 shows the TF coil thickness as a function of $\Delta_{\mathrm{BS}}^{\mathfrak{i}}$ for the same cases of fig. 12. For $\Delta_{B S}^{i}>1 \mathrm{~m}$ increasing $\Delta_{B S}^{i}$ increases the magnet thickness because of the increase in $B_{m}$ (see fig. 6). The abrupt increase in the magnet thickness for $R=7 \mathrm{~m}$ and $R=8 \mathrm{~m}$ at $\Delta_{B S}^{i} \sim 0.9 \mathrm{~m}$ and $\Delta_{B S}^{i} \sim 1.2 \mathrm{~m}$, respectively is due to the "switch" from $\mathrm{bTi}^{\mathrm{T}}$ to $\mathrm{Nb}_{3} \mathrm{~S}$ when $\mathrm{B}_{\mathrm{m}}$ exceeds $9 \mathrm{~T}$. The important observation to be made from fig. 13 is that for small values of $\Delta_{B S}^{i}$ the magnet thickness increases as $\Delta_{B S}^{i}$ is decreased despite the fact that $B_{m}$ is smaller. The reason is primarily due to the additional amount of copper required at higher radiation level to compensate for the increase in $\rho_{r}$. A much smaller contribution to the increase in the magnet thickness comes from increasing the amount of superconductor to compensate for the decrease in $J_{c}$.

In carrying out the parametric study discussed above, we purposefully assumed that all insulators will perform satisfactorily for the lifetime of the plant in all cases. However, table 3 shows the actual dose in the TF magnet insulators as a function of $A_{B S}^{i}$, at the end of plant life of $30 \mathrm{yr}$. Shown also in the table is the cost of energy for $R=6 \mathrm{~m}$. For the optimum shield, $\Delta_{B S}^{i} \sim 1 \mathrm{~m}$, the maximum dose in the insulator is $1.8 \times 10^{10} \mathrm{rad}$. Therefore, TF insulators that can function properiy up to that dose level are required in order to operate tokamaks in economically optimum conditions. As mentioned earlier, radiation damage data on organic insulators at $\sim 4^{\circ} \mathrm{K}$ are lacking. Extrapolation of irradiation data at higher temperatures show that mylar can be operated up to a dose of $210^{8}$ rad (region $M$ in fig. 1!) and that epoxy-base insulators can withstand higher doses of $210^{9}-5 \times 10^{9} \mathrm{rad}$ (region $\mathrm{E}$ in fig. 11). Table 3 shows that such 1 imits would dictate the use of a thicker shield and result in higher costs of energy than what is achievable otherwise. Therefore, accurate low-temperature irradiation data for organic insulators is necessary. These results may prove the need for development of new ductile and more radiation-resistant insulators or new concepts for magnet design that can permit the utilization of inorganic insulators. 
It shou?d be recalled that the values of $\Delta_{B S}^{i}$ used in this section represent the actual physical distance from the first wall to the inner edge of the TF coil winding (location of maximum magnetic field) in the midplane. Thus, the dimension of $\Delta_{B S}^{i}$ includes not only the blanket/shield thickness but also the non-attenuating space for maintenance, clearance, and thermal-insulation vacuum gap. For $\Delta_{B S}^{i} \sim 1 \mathrm{~m}$, the net thickness of the blanket/shield based on theoretical density of the shield materials is only $0.87 \mathrm{~m}$.

\section{Radiation Characteristics in Superconducting Magnets}

In the previous sections, typical characteristics of the radiation environments expected in tokamak superconducting TF magnets were given. The purpose of this section is to discuss in more detail the radiation levels and spectra at and within the tokamak magnets. It should be clearly noted that tokamak reactors are in the stage of active research and development. Present design concepts are continually revised and new ones are developed. Therefore, it is not possible to predict today all the specific features of the ultimate commercial tokamak power reactors that will prove the most attractive. To reach the goal of defining the most promising design point for a tokamak, a great deal of new knowledge has to be acquired and extensive experimental and analytical information needs to be developed. This information should cover a wide range of variables and a broad spectrum for each variable. An example of such inforamtion is the quantitative radiation effects in superconducting magnets. In the previous section we derived, based on present knowledge, an optimum design point and defined the corresponding maximum radiation levels in the Tf magnets. These levels should not be considered as the maximum required for new experimental and analytical information. Accurate inforamtion that extends to higher radiation levels is needed in order to quantify 
to a better accuracy all the tradeoffs in tokamak designs. Results presented below should be useful in defining the range of interest for radiation environment in superconducting magnets.

Figures 14-18 show the neutron flux and various radiation damage indicators in the elemental components of a TF magnet as a function of the spatial depth within the magnet. Prior to any specific discussion of these figures, one should note a few general rules about the absolute values and the spatial dependence of radiation-related parameters in the TF magnets. The maximum value of neutron and garma flux, atomic displacement, gas production, or any other neutronics response rate in the magnet depends on (1) the material composition in the blanket/shield; (2) $\Delta_{\mathrm{BS}}^{i}$ and/or $\Delta_{\mathrm{BS}}^{0}$; and (3) the neutron wall loading. The results that we selected for presentation in these figures are based on the blanket/shield system that evolved fron the tradeoff studies discussed in the previous section. The inner blanket/shield in this system consists of stainless steel and boron carbide with $\Delta_{B S}^{i}=1 \mathrm{~m}$. Variation of the neutronics response values in the magnet with $\Delta_{B S}^{i}$ can be easily inferred from results in the previous section. There is approximately an order of magnitude reduction in the maximum values at the TF magnet for every $\sim 0.17 \mathrm{~m}$ increase in $\Delta_{\mathrm{BS}}^{i}$. Dependence of these values on the blanket/shield composition and specific design considerations is available in the literature (see for example, ref. 12). All neutron and gamma-ray fluxes, reaction, atomic displacement, and nuclear heating rates, vary linearly with the neutron wall loading, $P_{w^{*}}$. Tokamaks will operate in the range of $P_{w} \approx 1-5 \mathrm{MW} / \mathrm{m}^{2}$. Time-integrated quantities such as atomic displacements and gas production are also linearly proportional to the operation time $t_{0}$, and hence they vary linearly with the integral neutron wall loading $I_{W}=P_{W} t_{0} E$. The range of $t_{0}$ was discussed in the previous section. 
For radiation effects that can be recovered, a reasonable rnage for $I_{w}=5-50$ $M W-y r / m^{2}$ and for irreversible radiation effects, the range of interest is $I_{w}=30-150 \mathrm{MW}-y r / \mathrm{m}^{2}$. For convenience, fig. is normalized to $P_{w}=1 \mathrm{~mW} / \mathrm{m}^{2}$ and figs. 15-18 are normalized to $1 \mathrm{MW}-\mathrm{yr} / \mathrm{m}^{2}$.

Figure 14 shows the total neutron flux and gamma-ray flux within the TF magnet. There is a factor of 10 reduction in every $20.3 \mathrm{~m}$. This attenuation factor depends on the amount of helium and vacuum space which was assumed here to be $15 \%$ of the magnet volume. Shown also in the figure is the neutron flux for neutrons with energies $>8 \mathrm{MeV}$. About $2 \%$ of the neutrons at the edge of the magnet have such high energies. This fraction also varies with $\Delta_{B S}^{i}$ and the composition of the shield.

Figure 15 shows the spatial distribution of atomic displacements in aluminum, copper, and niobium in units of dpa/(MH-yr/min $\left.{ }^{2}\right)$. Displacement energies employed in these calculations are 26, 40, and $60 \mathrm{eV}$ for aluminum, copper, and niobium, respectively. The radiation-induced resistivity in copper and aluminum varies exponentially with the dpa level as discussed earlier in this paper. It should be noted here that the radiation-induced resistivity is higher in aluminum than in copper because of the higher dpa and larger saturation resistivity in aluminum. Hydrogen and helium production rates within the TF magnet are shown in figs. 16 and 17 for stainless steel, copper, aluminum, and niobium. Helium and hydrogen productions in stabilizing materials (aluminum and copper) are higher than in the superconductor ( $\left(1 \mathrm{~b}_{3} \mathrm{Sn}\right.$ or $\left.\mathrm{NbTi}\right)$. Both are in the range of $10^{-4}$ to $10^{-3} \mathrm{appm} /\left(\mathrm{m}-\mathrm{yr} / \mathrm{m}^{2}\right)$. Thus, total gas production in the range of 0.001 to 0.1 appm is expected in the TF magnet conductors at end of plant life. The concentration of impurities due to all transmutations by nuclear reactions is heavily dependent on the neutron spectrum at the magnet but it is generally one to two orders of magnitude higher than 
the gas production. About $70 \%$ of all neutron transmuting reaction rates come from the $(n, \gamma)$ reaction. The important impurities produced by nuclear transmutations are nickel, zinc, and cobalt in copper; and silicon and magnesium in aluminum. The total impurity concentration in copper and aluminum is 0.01 and 0.002 appm/(MW-yr/m $\left.{ }^{2}\right)$, respectively. Thus, at the end of the plant lifetime, the maximum impurity concentration in the magnet is roughly 1 appm.

Figure 19 shows three neutron spectra, $A, B$, and $C$. Curves $A$ and $B$ represent the neutron spectra obtainable in tokamaks with an inner blanket/shield of stainless steel-boron carbide in two locations. Location $B$ is the innermost layer of the TF coil located $1 \mathrm{~m}$ ailay from the first wall. Location $A$ is $0.6 \mathrm{~m}$ away from the first wall which is a typical location for the equilibrium-field (EF) coils if they are located inside the shield. Curve $C$ represents the neutron spectrum obtainable in the ANL low-temperature fast flux facility. Figure 20 shows the fraction, $f\left(E_{0}\right)$, of the total neutron flux with neutron energies above $E_{0}$, as a function of $E_{0}$ for the same three fluxes, $A, B$, and $C$. The two figures show that a typical fission spectrum such as that of $C$ can simulate very well the neutron spectra in tokamak superconducting magnets for energies below $25 \mathrm{MeV}$. The fraction of neutrons above $0.1 \mathrm{MeV}$ in $\mathrm{C}(90 \%)$ is considerably greater than in $\mathrm{A}$ and $\mathrm{B}(260 \%)$. However, the fission spectrum (C) has a very small component (1.5\%) above $5 \mathrm{MeV}$ and essentially no neutrons above $8 \mathrm{MeV}$. The typical spectra in tokamak magnets ( $A$ and $B$ ) have $25 \%$ of the neutrons of energies $>5 \mathrm{MeV}$. Many neutron-induced reactions [e.g. $(n, \alpha)$, $(n, p),\left(n, n^{\prime} p\right)$, etc.] occur in typical magnet materials only at high energies. In addition, the recoil energy for a given reaction increases with neutron energy. Therefore, high energy neutrons are more capable of producing radiation damage than low energy neutrons. Thus, while fission spectra seem to be adequate for radiation damage experiments on superconducting magnets, the spectral differences in the fusion environments must be taken into account. It should be noted in thil regard that the total neutron flux is a poor radiation damage indicator in 
the wide fusion spectra: that extends from $20-15 \mathrm{MeV}$. Other radiation damage indicators, e.g. atomic displacements, that account, to some extent, for the energy dependence of the radiation effects should be used in correlating radiation damage and radiation levels. It would be useful to establish reference sets of damage functions for materials in superconducting magnets that can be used by radiation damage experimentalists and fusion reactor designers.

The neutron spectra at the TF magnet will change for other shieiding material compositions. In general, the fraction of neutrons at high energy will decrease as the shield thickness is increased. 


\section{References}

[1] Proceedings of BNES Nuclear Fusion Conference, Culham (1969).

[2] A. J. Impink, Jr., "Neutron Economy in Fusion Reactor Blanket Assemblies," Technical Report No. 434, MIT Research Laboratory of Electronics, Cambridge, Mass. (1965).

[3] J. T. Kriese and D. Steinar, Oak Ridge National Laboratory Report (USA) ORNL-TM-4853 (1973).

[4] M. A. Abdou and C. W. Maynard, Proc. 1st Top. Mitg. Technology of Controlled Nuclear Fusion, USAEC-CONF-140402-P1, Vol. I (1974), p. 685.

[5] G. M. McCracken and S. Blow, Culham Laboratory Report CLM-R-120 (1972).

[6] W. J. Stacey, Jr. and M. A. Abdou, Argonne National Laboratory Report ANL/FPP/TM-83 (1977).

[7] M. A. Abdou, et al., "Parametric Systems Analyses for Tokamak Power Plants," Argonne National Laboratory Report (to be published).

[8] W. M. Stacey, Jr., et al., Argonne National Laboratory Report ANL/CTR-76-3 (1976).

[9] D. R. Cohn, et al., Proc. 2nd Top. Mtg. on the Technology of Controlled Nuclear Fusion, USERDA-CONF-60935-P3 (1976), p. 931.

[10] D. W. Kearney, et al., General Atomics (USA) Report GA-Al3992 (1976). 
Table 1

Reference parameters for cases in fig. 11

Neutron wall loading, $\mathrm{MW} / \mathrm{m}^{2}$

Reactor thermal power, MW

$R=6 \mathrm{~m}$
$R=7 \mathrm{~m}$
$R=8 \mathrm{~m}$
$R=9 \mathrm{~m}$

1950

2620

3390

4260

Aspect ratio

3

Period between magnet anneals, yr

11.4

Downtime for magnet anneal, days

80

Table 2

Radiation parameters (maximum values) in the TF superconducting magnet at $\Delta_{B S}^{i}=1 \mathrm{~m}$

Neutron flux, $\mathrm{m}^{-2}-\mathrm{sec}^{-1}$

Gamma-ray flux, $\mathrm{m}^{-2}-\mathrm{sec}^{-1}$

Maximum neutron fluence at magnet anneal, $\mathrm{m}^{-2}$

Maximum gamma-ray fluence at magnet anneal, $\mathrm{m}^{-2}$

Radiation-induced resistivity in copper, $\Omega-\mathrm{cm}$

Decrease in NbTi critical current density, $\Delta \mathrm{J} / \mathrm{J}_{\mathrm{c}}$

Nuclear energy deposition, $\mathrm{kW}$

$R=6 \mathrm{~m}$

$R=7 \mathrm{~m}$

$R=8 \mathrm{~m}$

$R=9 \mathrm{~m}$
$1.4 \times 10^{14}$

$9 \times 10^{13}$

$4.5 \times 10^{22}$

$2.9 \times 10^{22}$

$1.05 \times 10^{-7}$

214\%

\section{9}

7.9

10.3

12.9 
Table 3

Effect of inner blanket/shield thickness

on maximum dose to the insulators in the toroidal-field magnets*

\begin{tabular}{|c|c|c|}
\hline \multirow{2}{*}{$\begin{array}{l}\Delta_{\mathrm{BS}}^{\mathbf{j}} \\
(\mathrm{m})\end{array}$} & \multirow{2}{*}{$\begin{array}{l}\text { Dose to insulator } \\
\text { at end of plant } \\
\text { Life, } 30 \text { yr } \\
\text { (rad) }\end{array}$} & \multirow{2}{*}{$\begin{array}{c}\begin{array}{c}\text { Cost of Energy } \\
\text { mills /kWh }\end{array} \\
R=6\end{array}$} \\
\hline & & \\
\hline 0.7 & $1.2 \times 10^{12}$ & 55.2 \\
\hline 0.8 & $3 \times 10^{11}$ & 37.6 \\
\hline 0.9 & $7 \times 10^{10}$ & 34.5 \\
\hline 1.0 & $1.8 \times 10^{10}$ & 34.4 \\
\hline 1.1 & $3.3 \times 10^{9}$ & 35.2 \\
\hline 1.2 & $1.2 \times 10^{9}$ & 37.1 \\
\hline 1.3 & $3 \times 10^{8}$ & 40.1 \\
\hline 1.4 & $7 \times 10^{7}$ & 45.4 \\
\hline
\end{tabular}




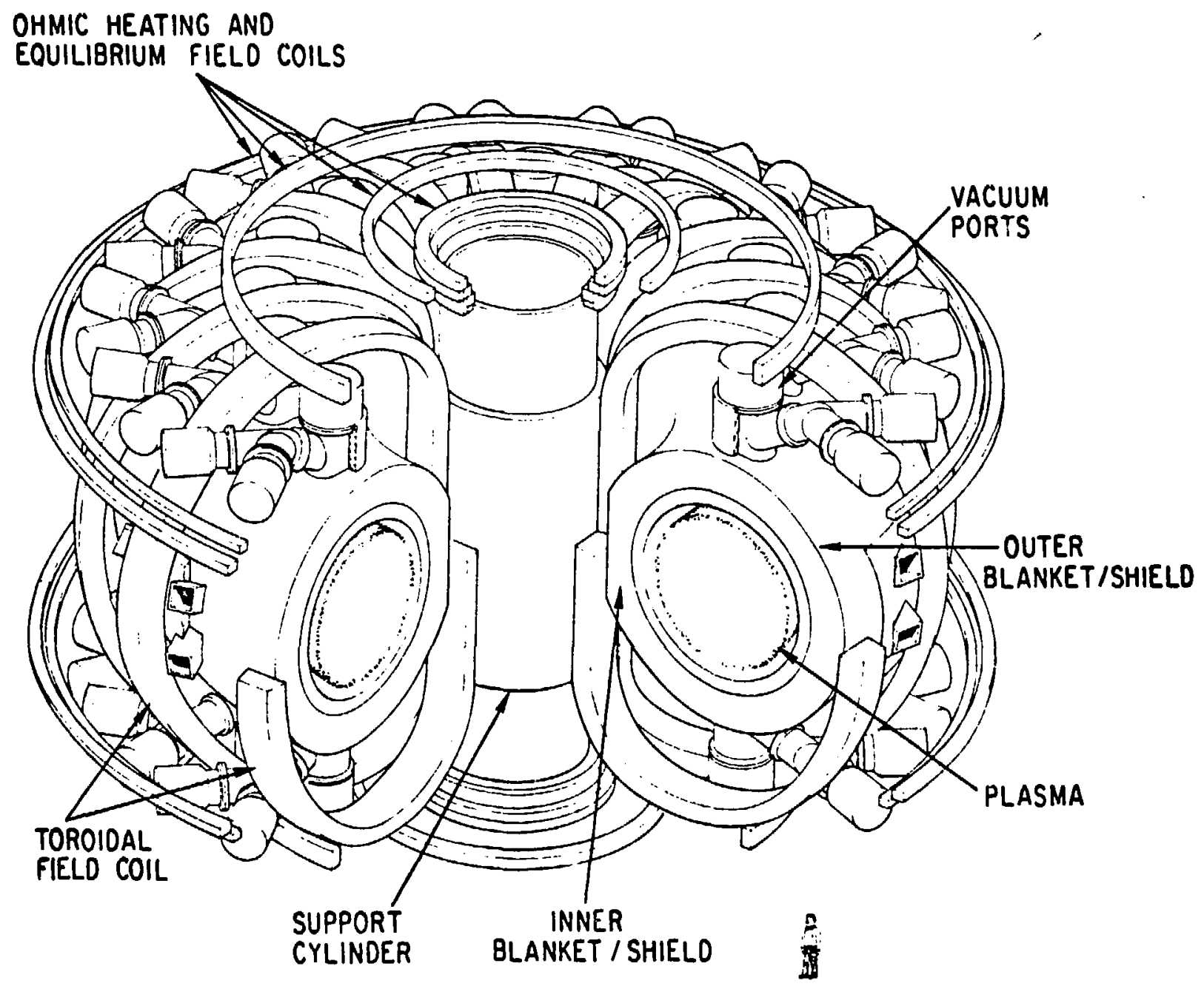

Fig. 1. Perspective view of a tokamak. 


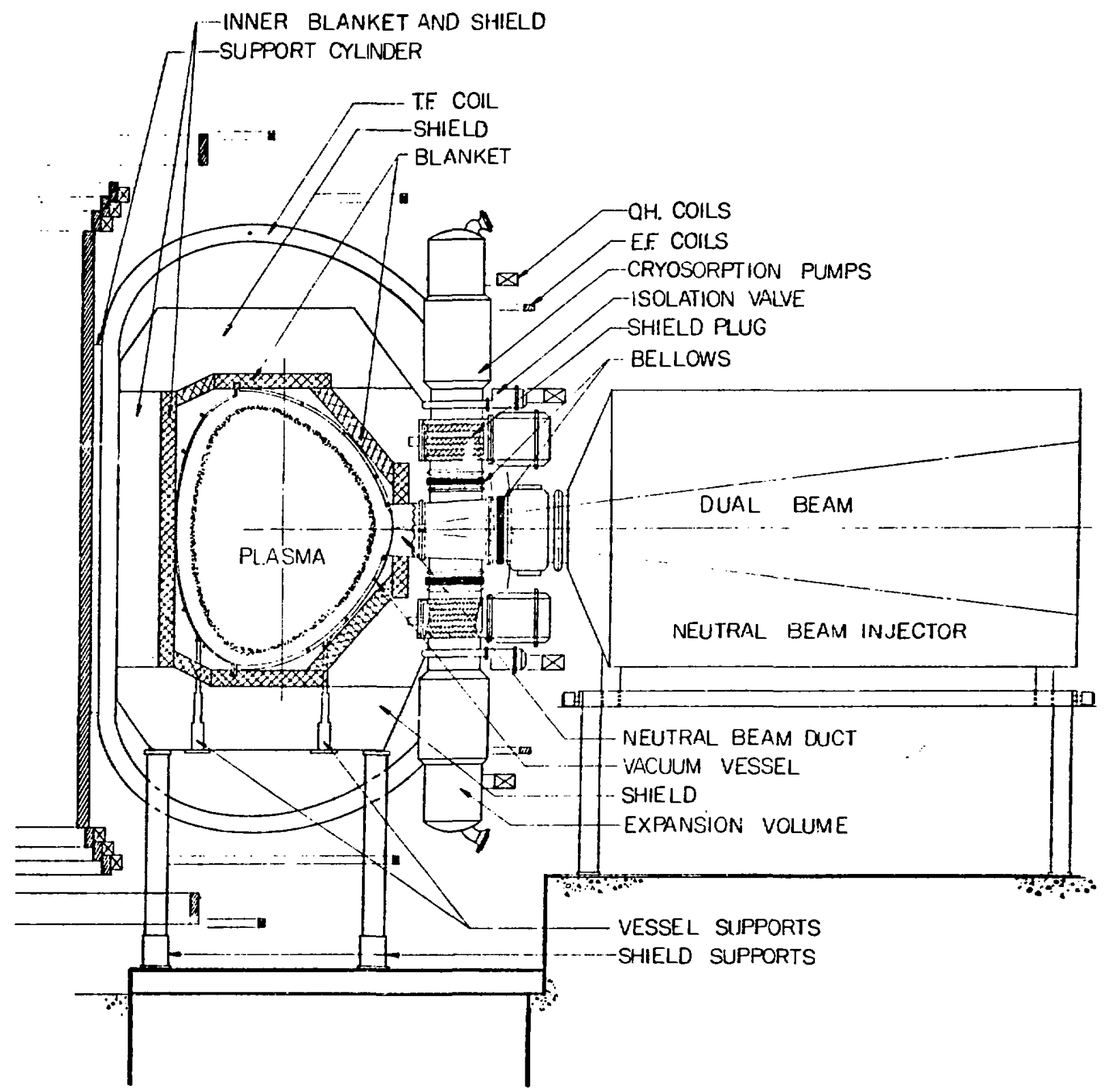

Fig. 2. Vertical cross section of a tokamak with a representative neutral beam penetration. 


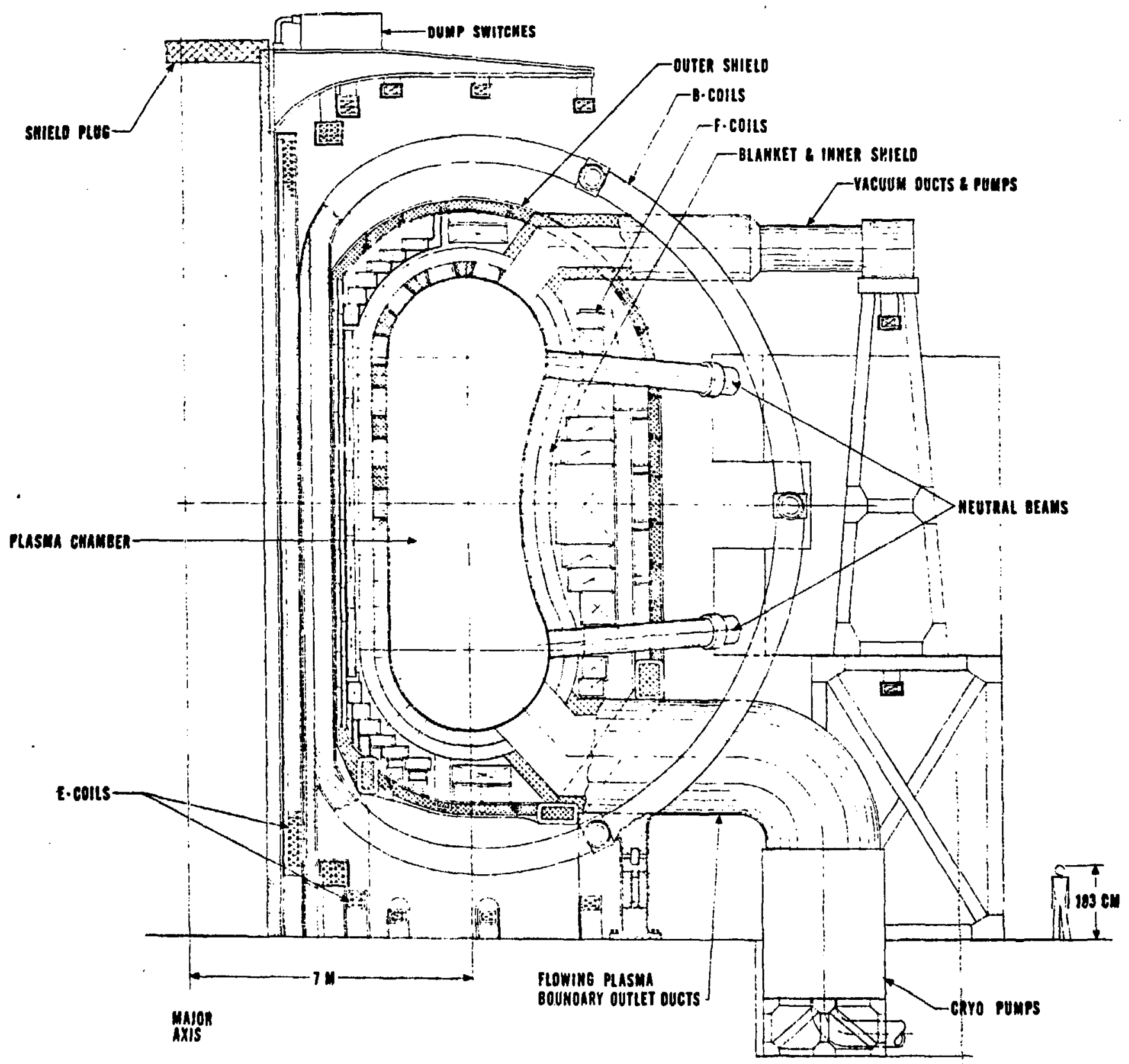

Fig. 3. Vertical cross section of a Doublet tokamak. 


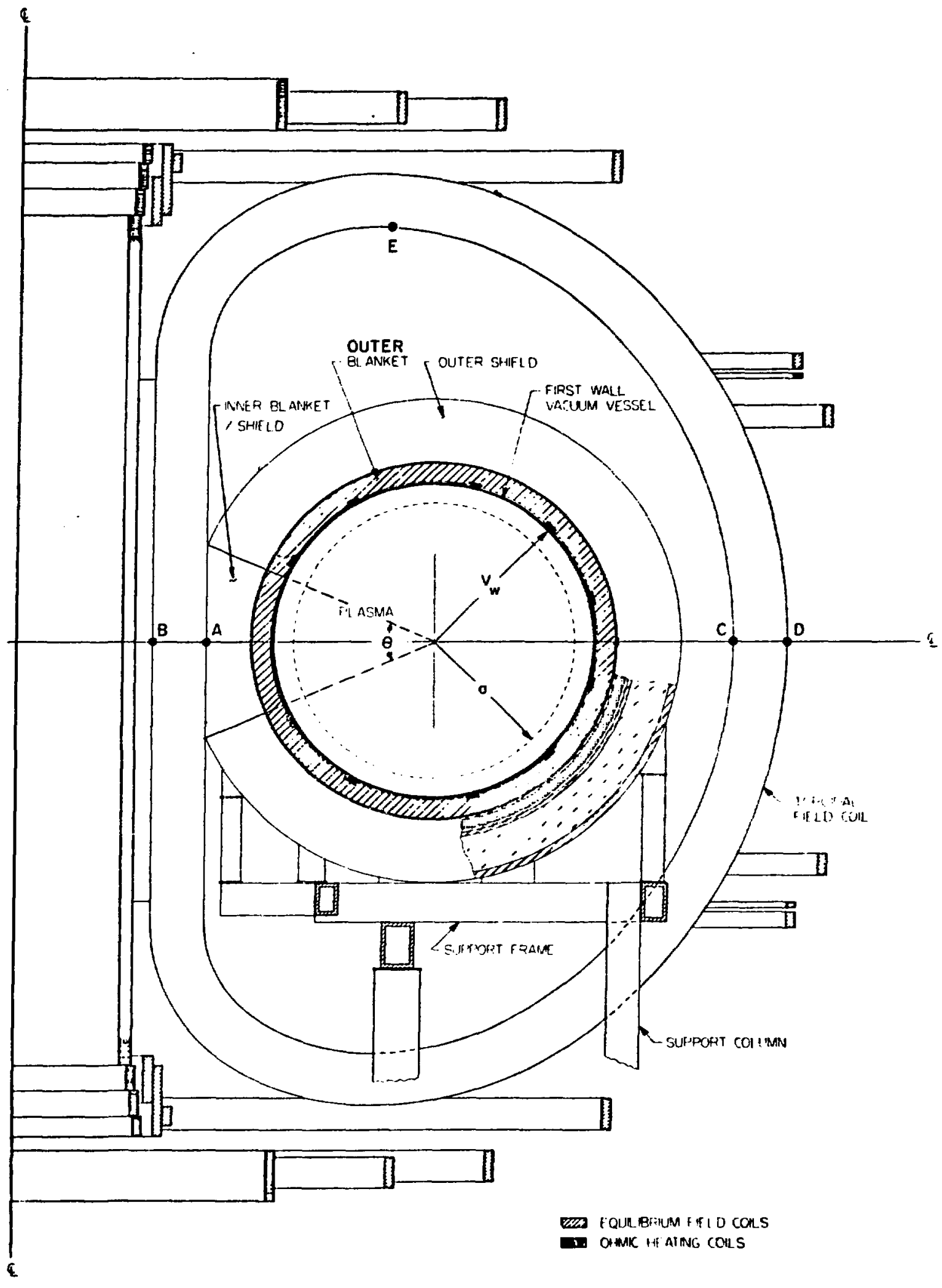

Fig. 4. A simplified vertical cross section of a representative tokamak with circuiar plasma. 


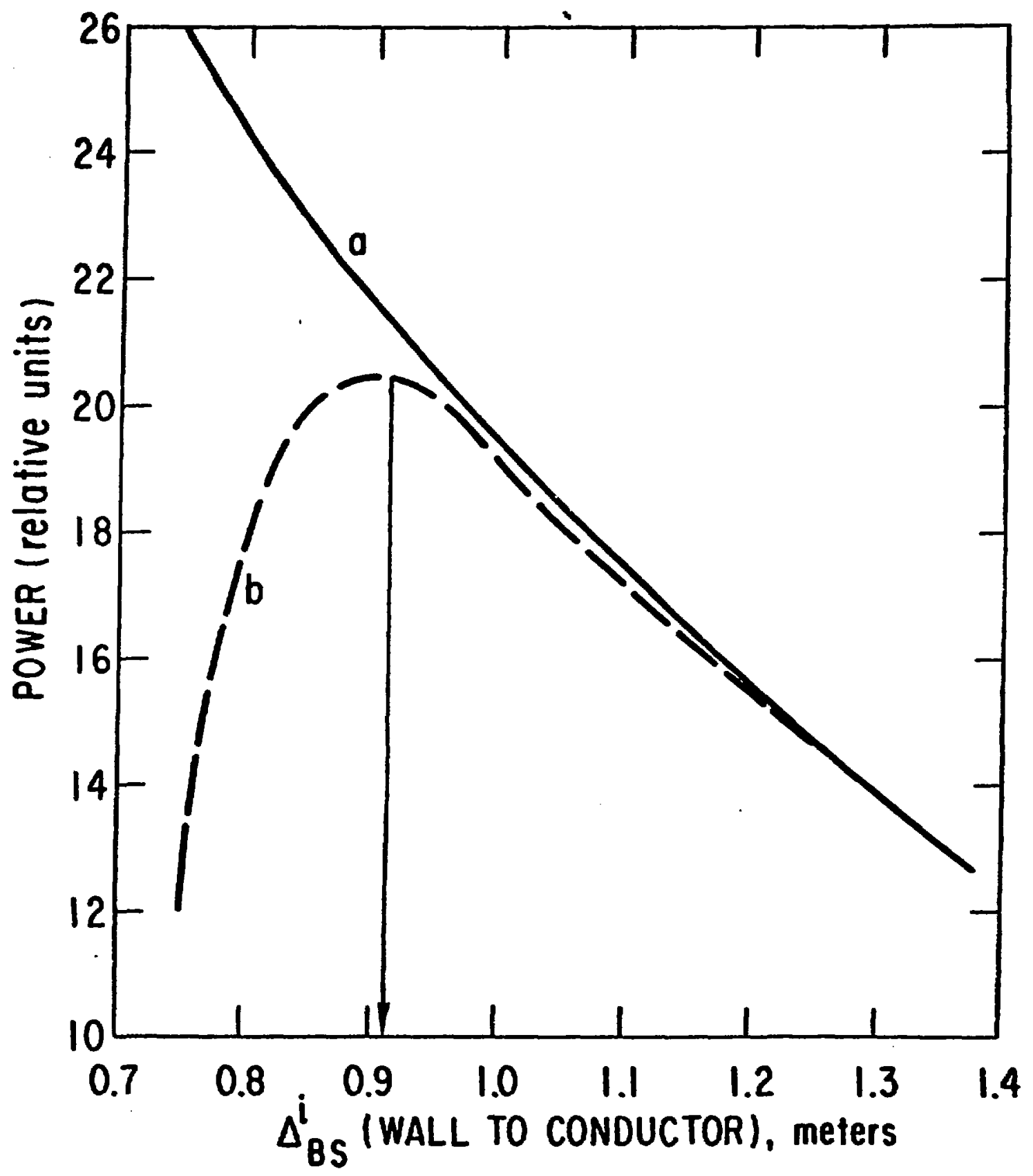

Fig. 5. Effect of inner blanket/shield thickness on (a) reactor gross electric power; and (b) reactor net electric power (= gross power-TF magnet refrigeration power). 


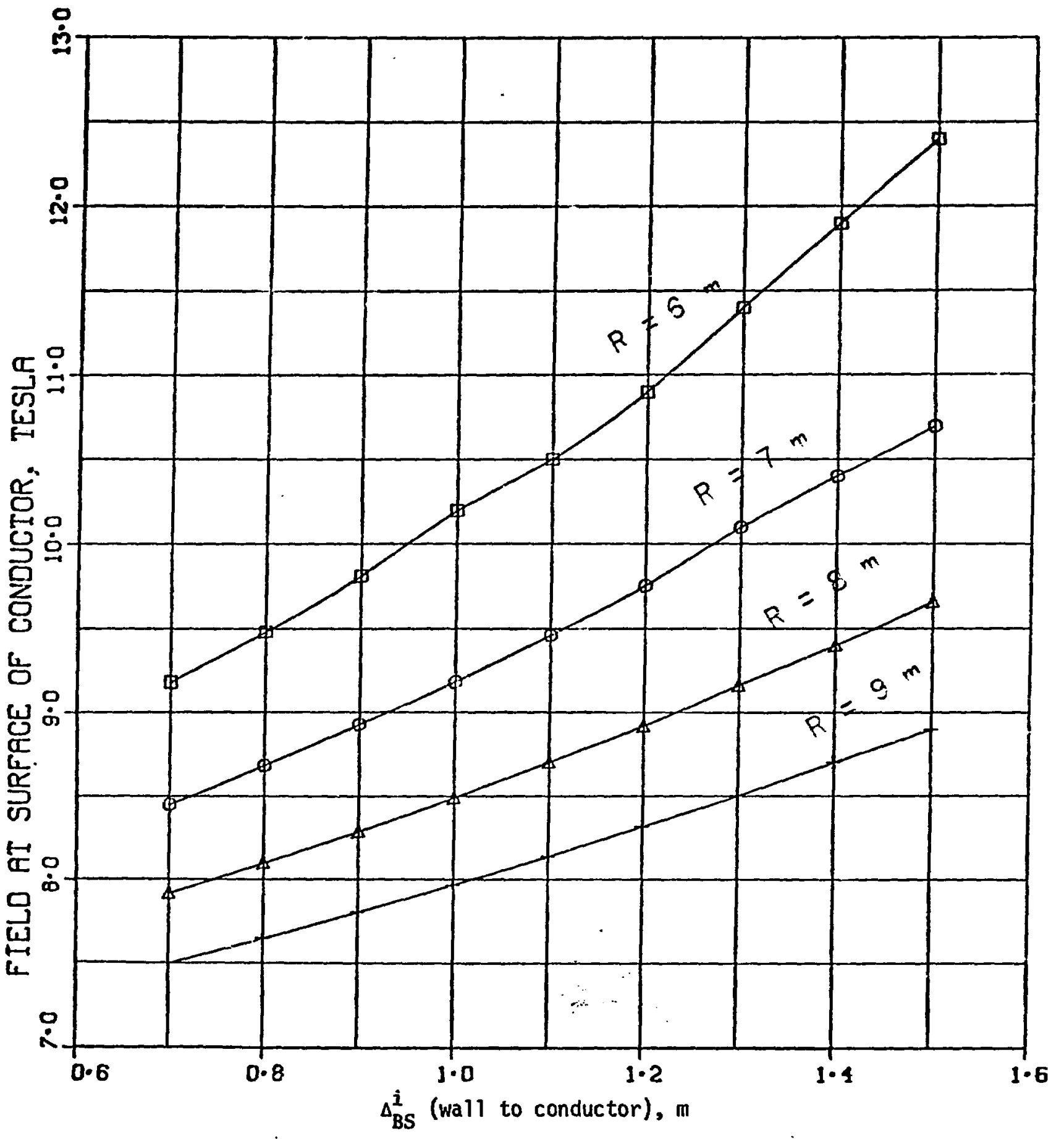

Fig. 6. Maximum magnetic field required to produce a fixed plasma power density as a function of the inner blanket/shield thickness. Results are shown for several values of the major radius, $R$, aspect ratio of 3 , and neutron wall load of $3 \mathrm{MW} / \mathrm{m}^{2}$ for circular plasma. 


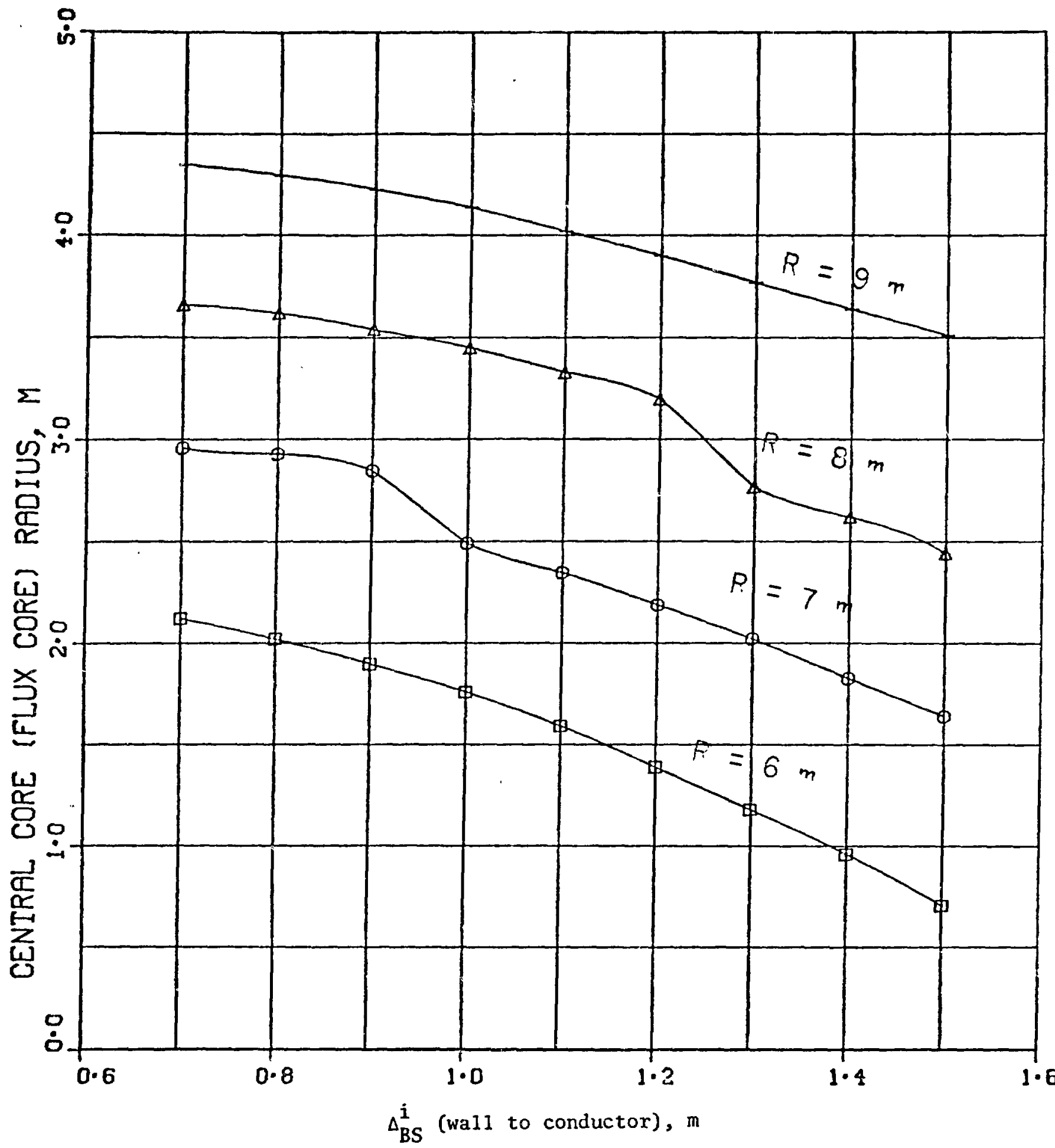

Fig. 7. Central core radius as a function of inner blanket/shield thickness for sevenai size tokamaks $\left(A=3, P_{w}=3 \mathrm{M} / \mathrm{m}^{2}\right.$, circular plasma $)$. 


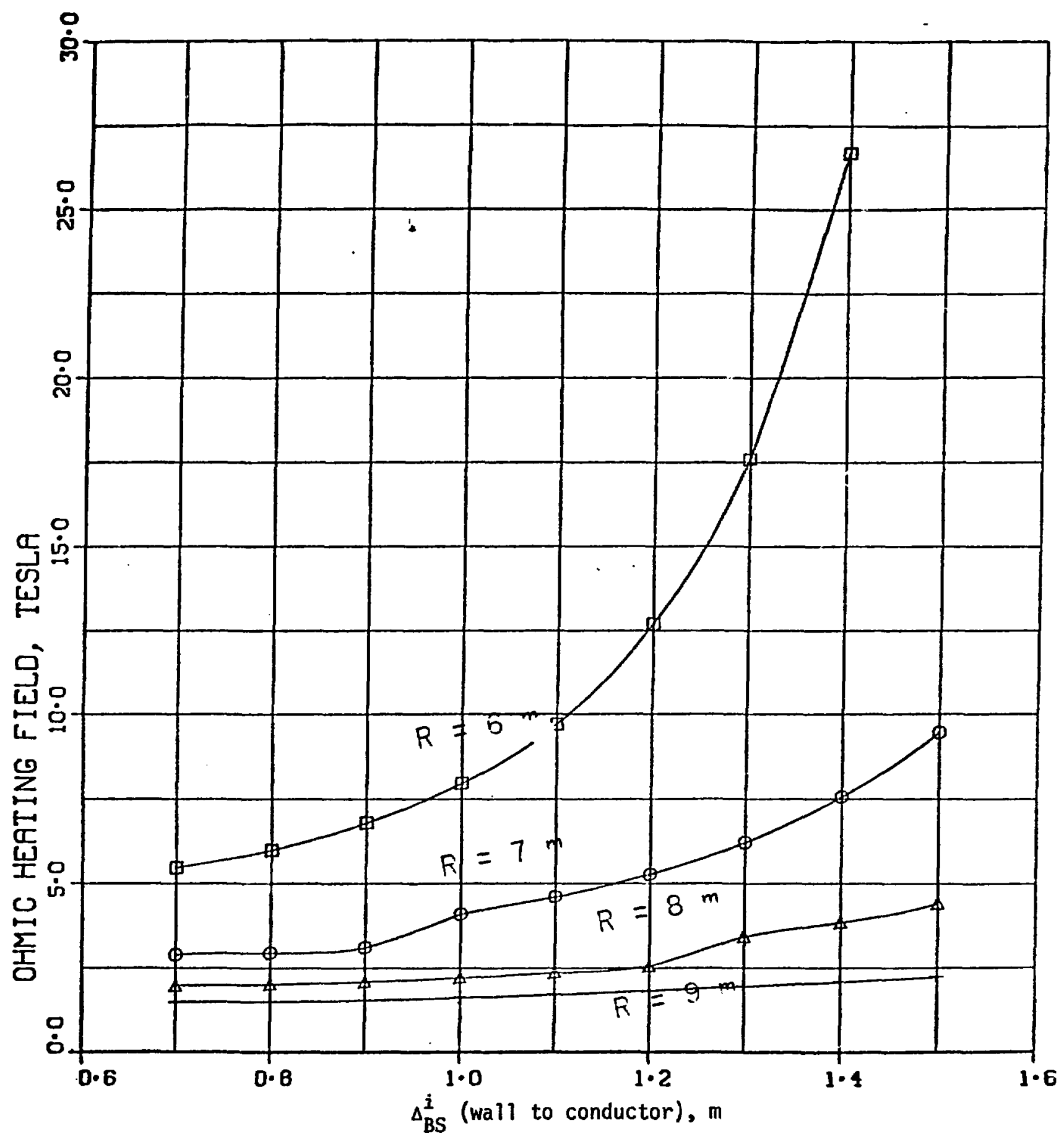

Fig. 8. Maximum ohmic heating field required in several size tokamaks as a function of inner blanket/shield thickness $\left(A=3, P_{w}=3 \mathrm{MW} / \mathrm{m}^{2}\right.$, circular plasma). 


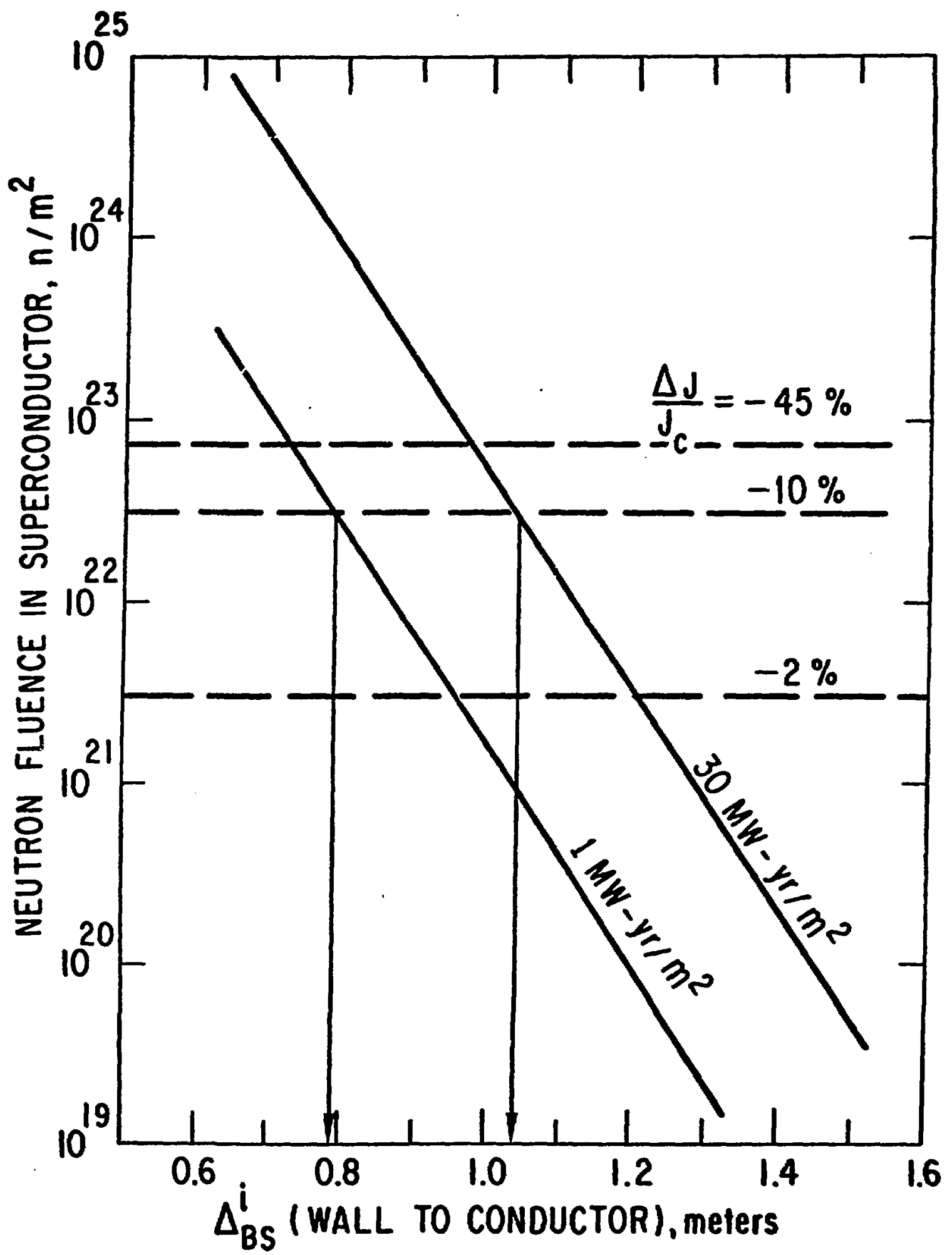

Fig. 9. Maximum neutron fluence in TF magnet as a function of inner blanket/shield thickness. 


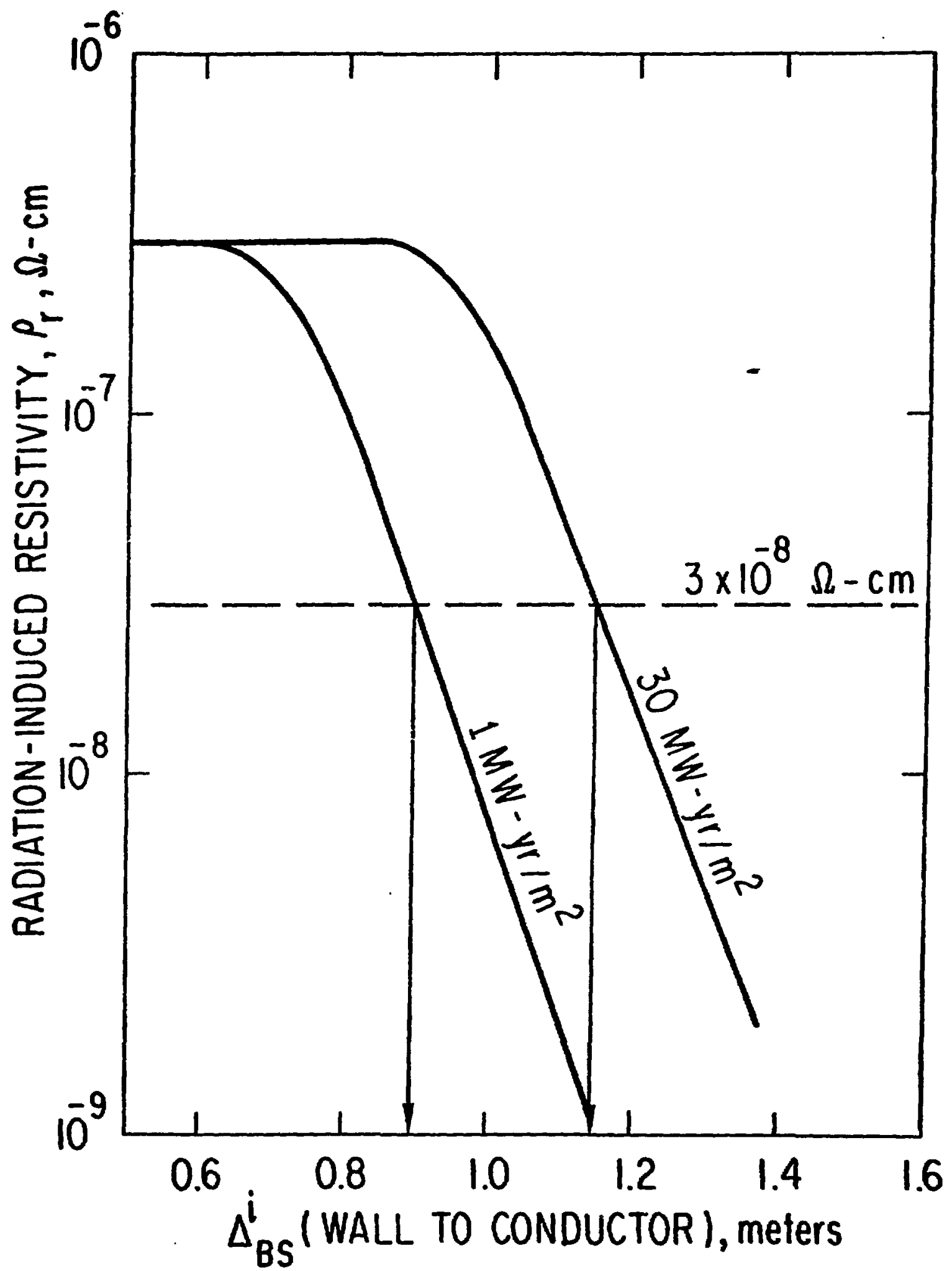

Fig. 10. Maximum radiation-induced resistivity in copper stabilizer . as a function of inner blanket/shield thickness. 


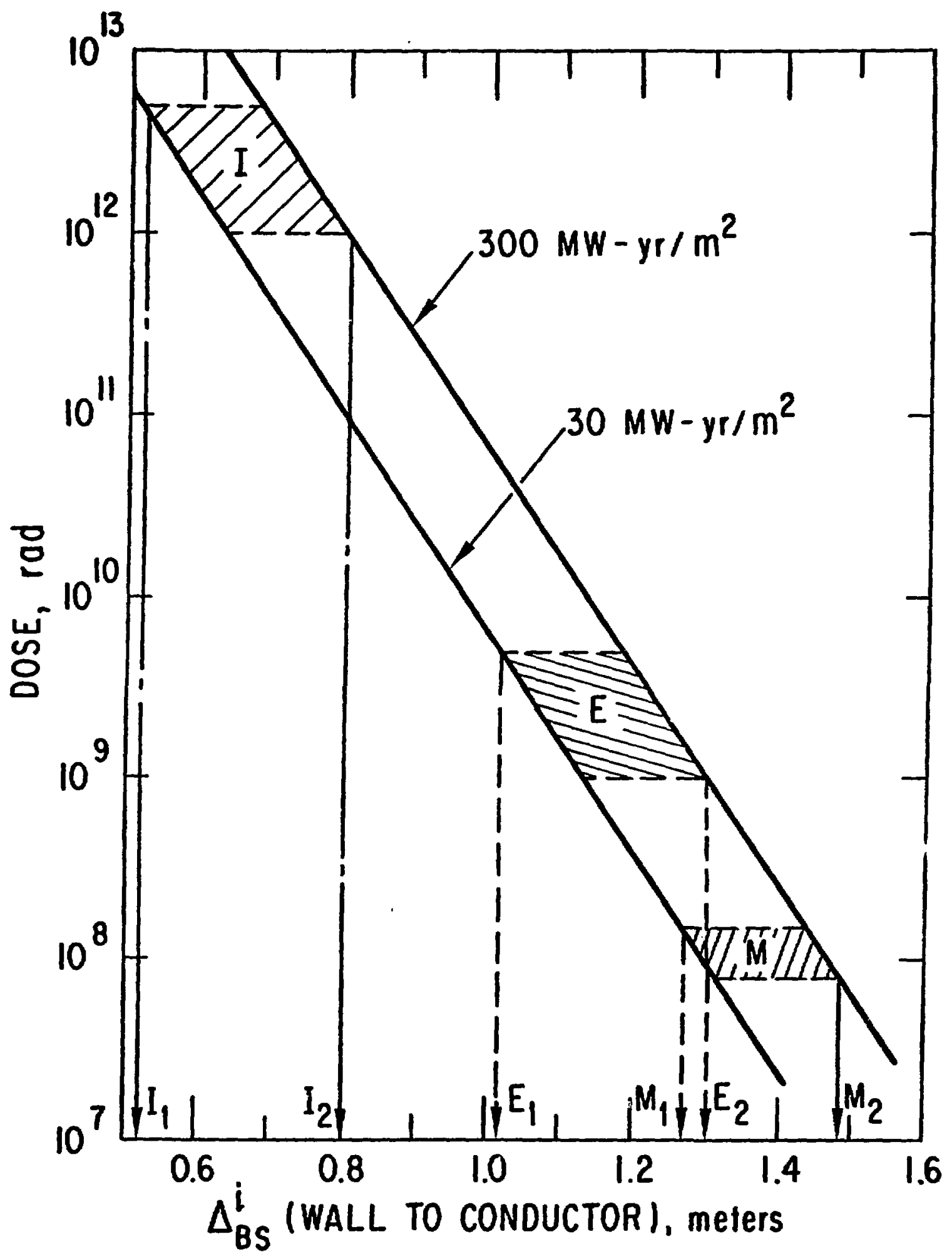

Fig. 11. Variation of radiation dose in TF magnet insulators with inner blanket/shield thickness. 


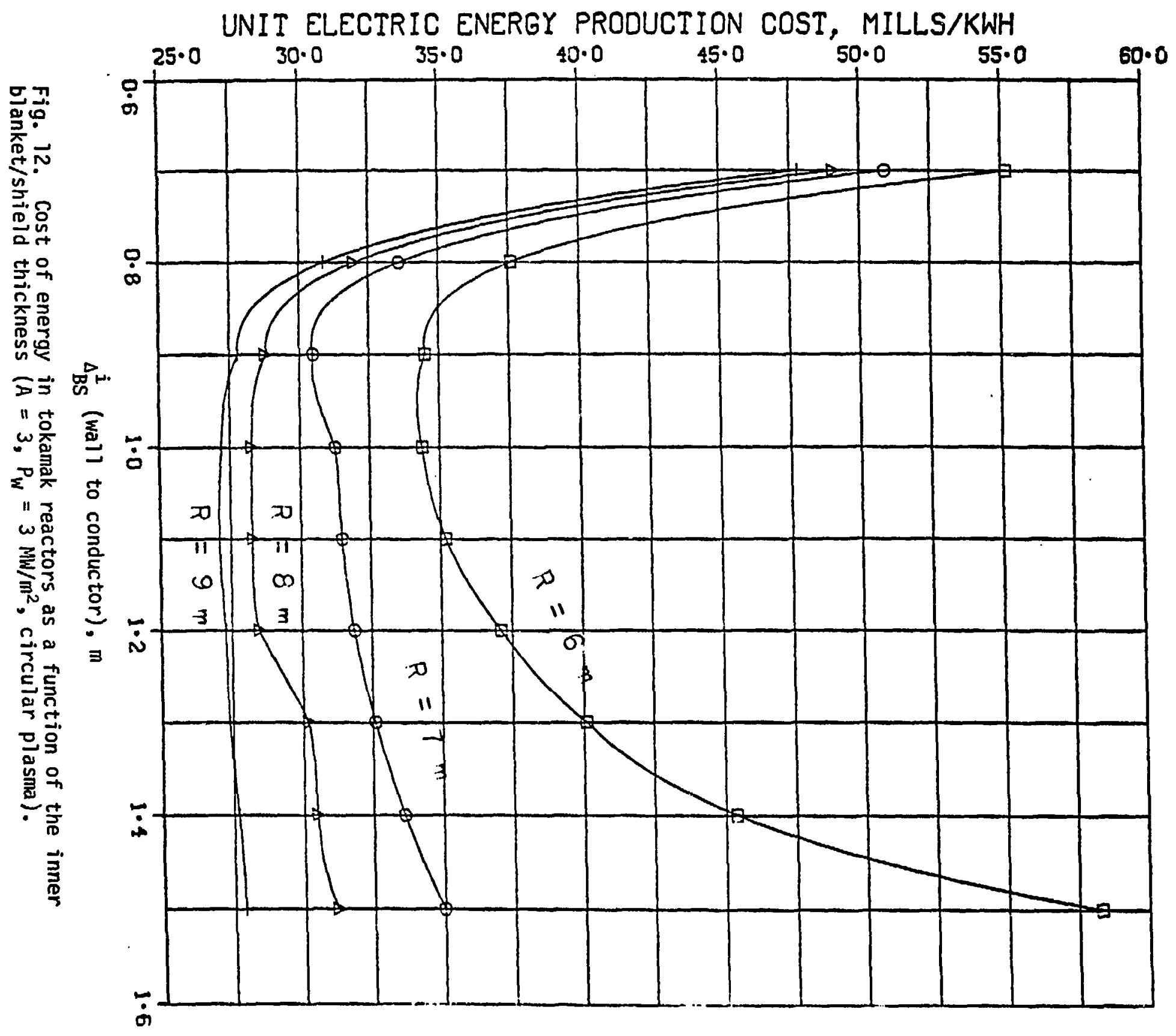




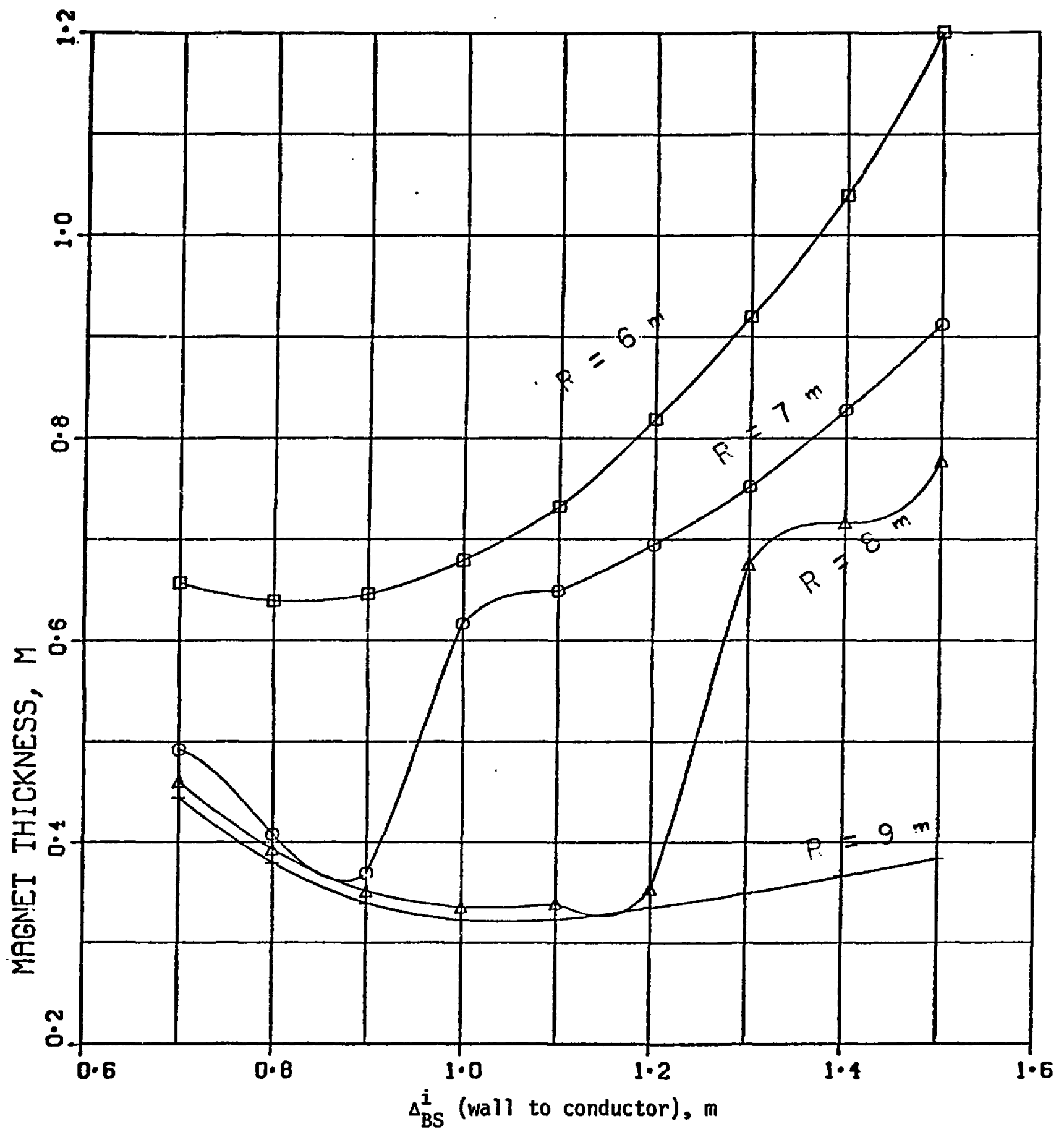

Fig. 13. TF magnet thickness as a function of blanket/shield thickness $\left(A=3, P_{W}=3 \mathrm{MW} / \mathrm{m}^{2}\right)$. 


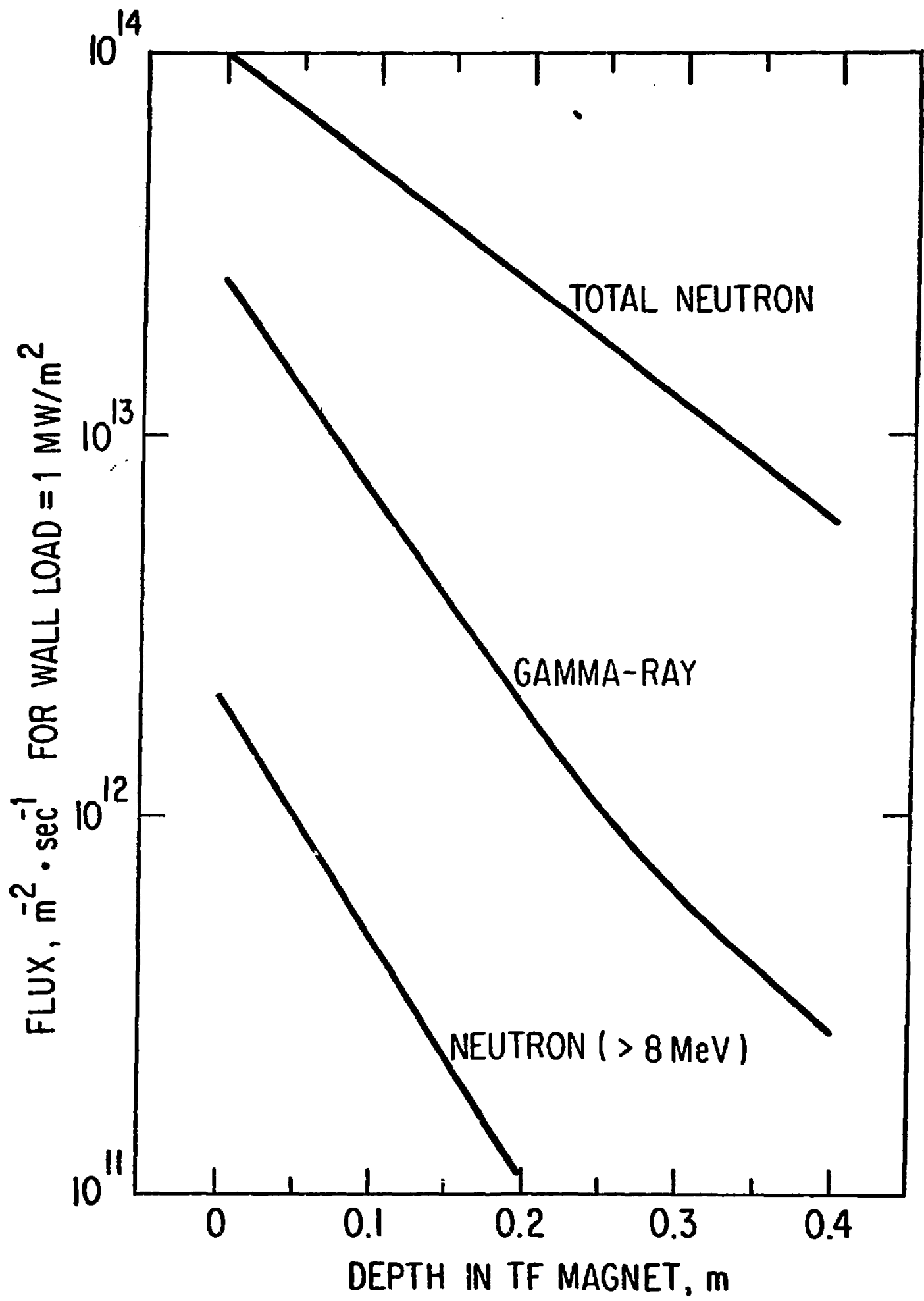

Fig. 14. Neutron and gamma-ray fluxes as a function of depth on the innerside of a TF magnet. 


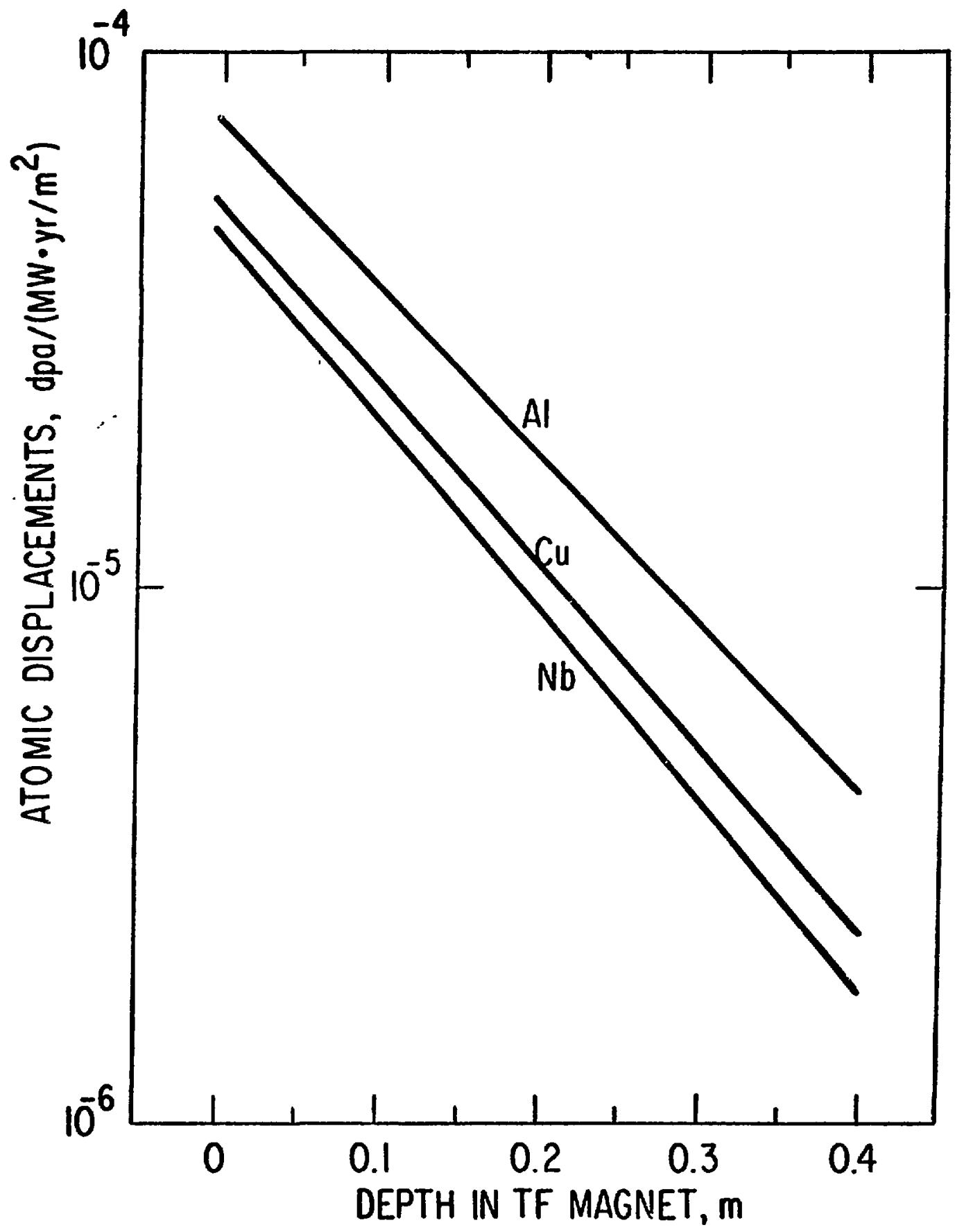

Fig. 15. Atomic displacements as a function of depth on the inner side of a TF magnet. 


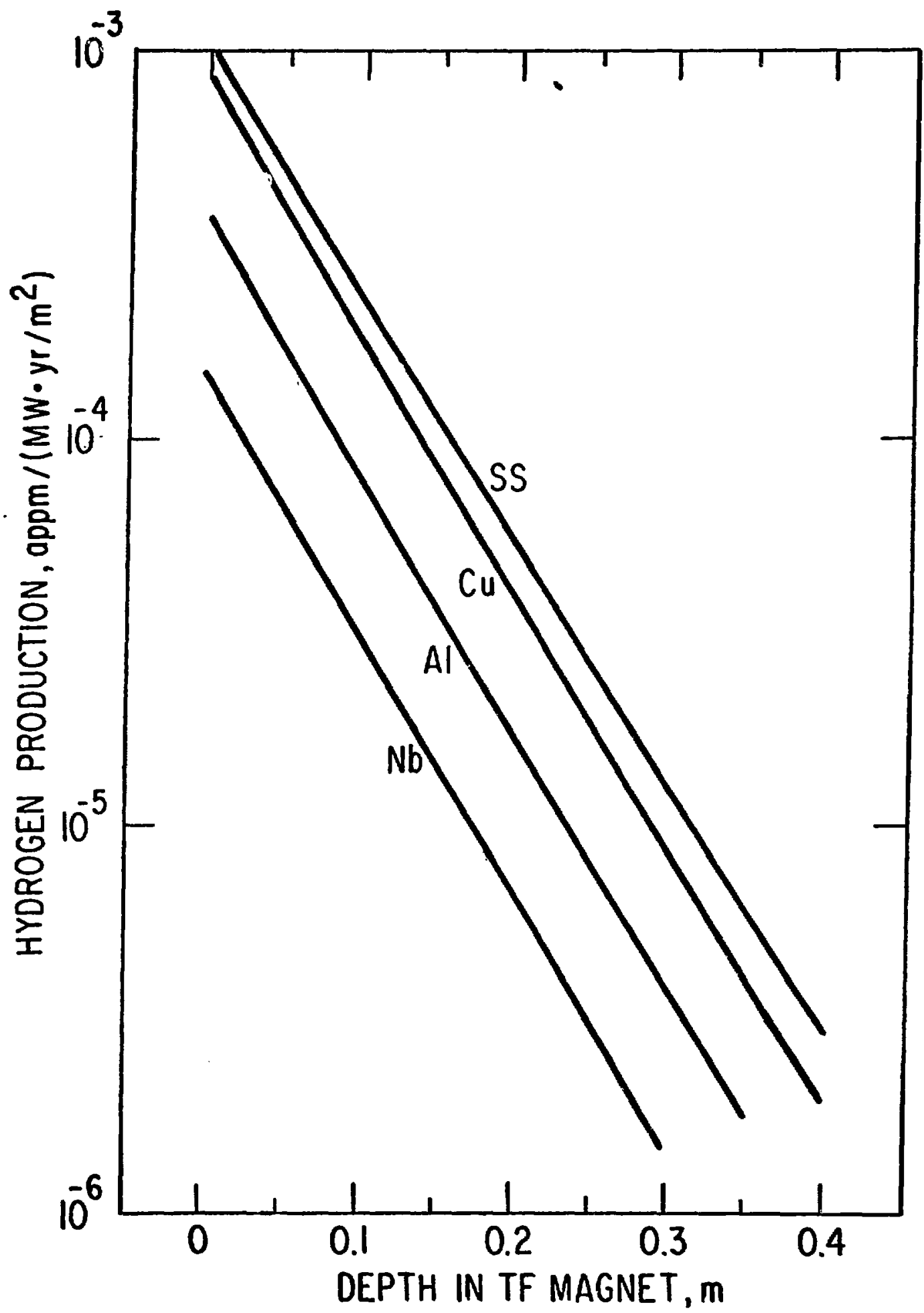

Fig. 16. Hydrogen production as a function of depth on the inner side .of, a TF magnet. 


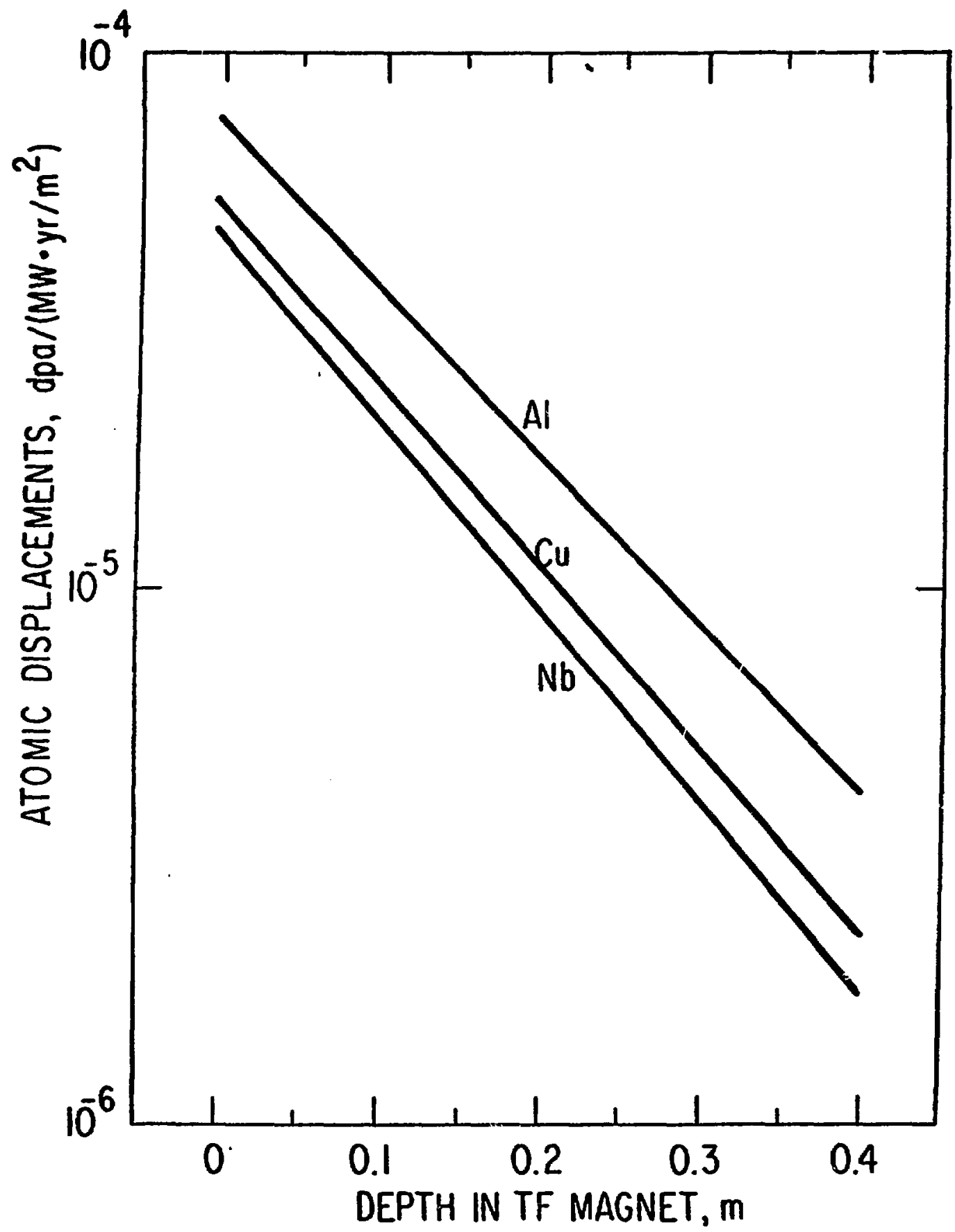

Fig. 17. Helium production as a function of depth on the inner side of a TF magnet. 


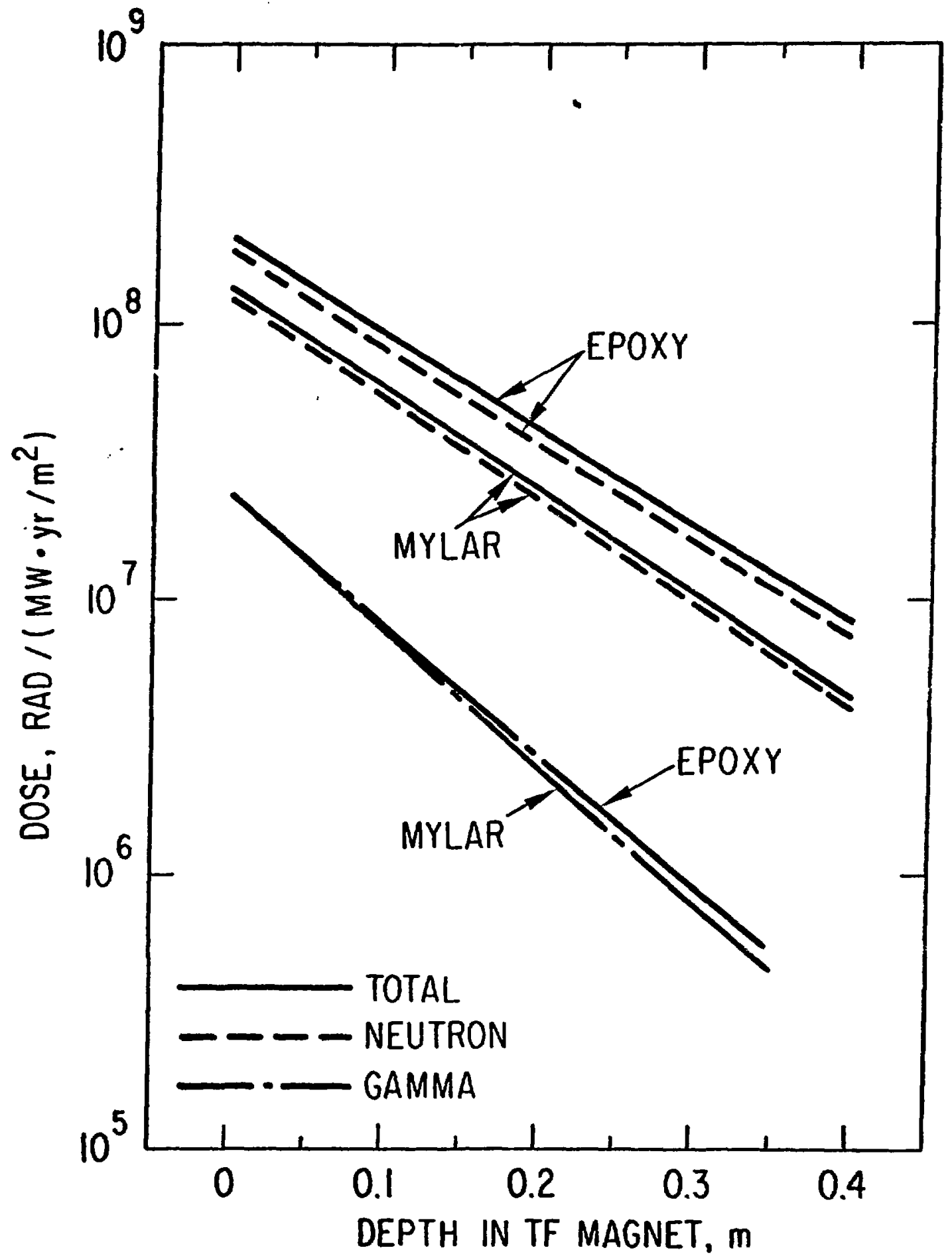

Fig. 18. Radiation dose in typical insulators as a function of depth on the inner side of a TF magnet. 


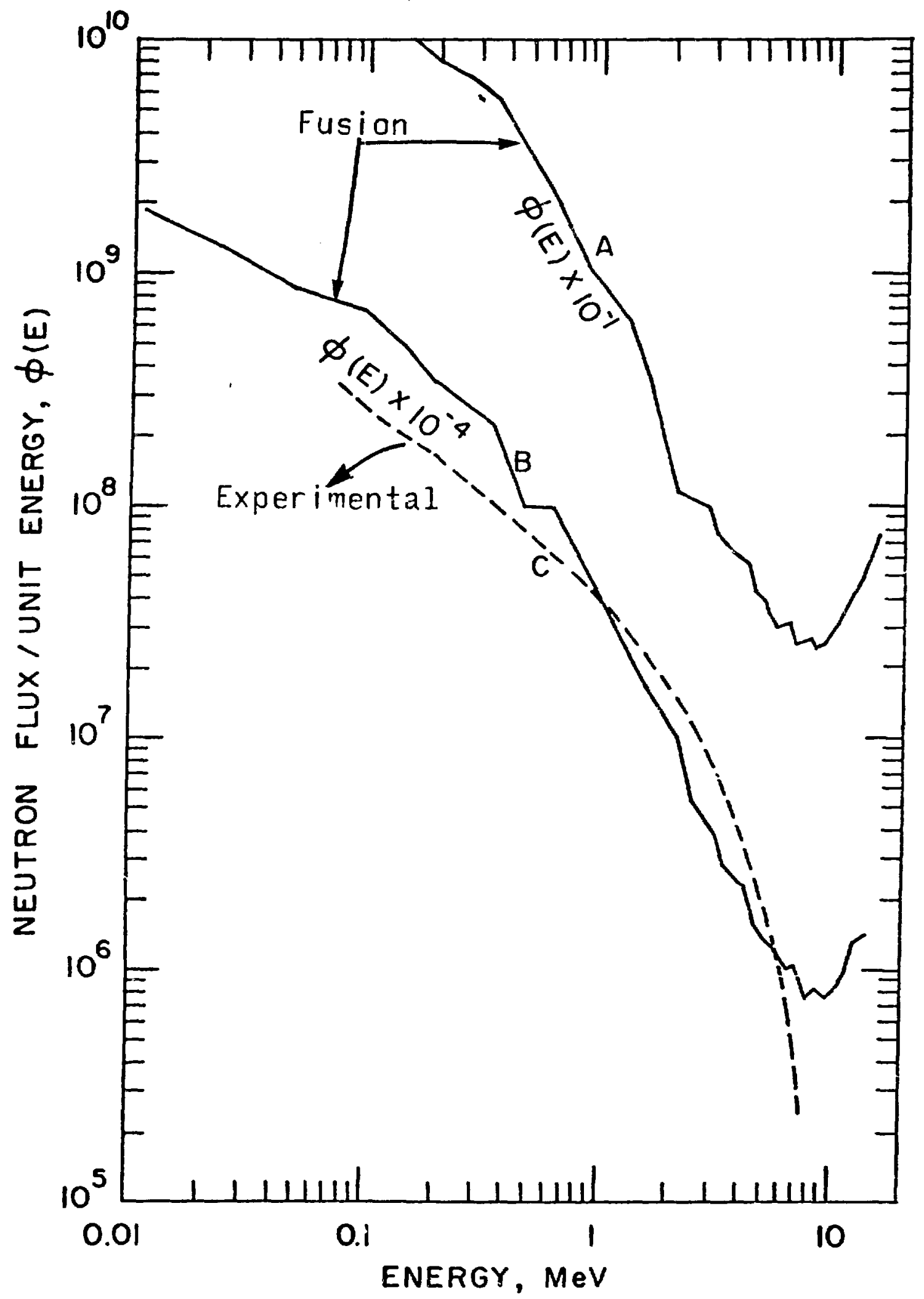

Fig. 19. Comparison of typical neutron spectra in tokamak magnets with typicai experimental (fission) spectrum: (a) neutron spectrum in a magnet located $0.6 \mathrm{~m}$ away from first wall; (b) neutron spectrum in TF magnet with inner blanket/shield of SS and $B_{4} C\left(\Delta_{B S}^{i}=1 \mathrm{~m}\right)$; and $(c)$ neutron spectrum for the ANL low-temperature facility. 


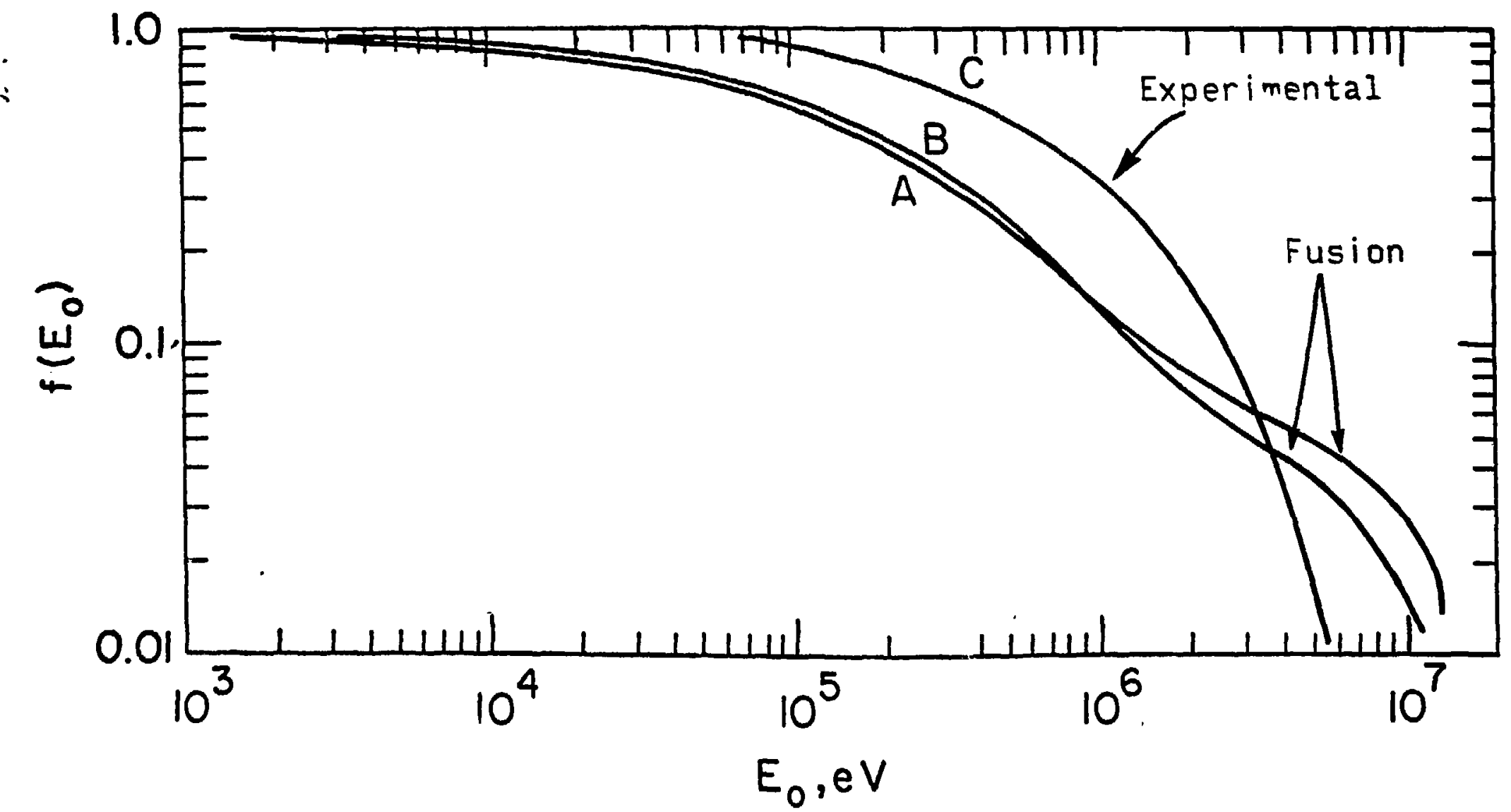

Fig. 20. The fraction, $f\left(E_{0}\right)$ of the total neutron flux with neutron energies above $E_{0}$ as a function of $E_{0}$ for the three cases $A, B$, and $C$ shown in Fig. 19 . 